\title{
Evolution of Permeability in Sand Injectite Systems
}

\author{
Yu Hu${ }^{1,3}$, Quan Gan ${ }^{1,3}$, Andrew Hurst ${ }^{1}$, Derek Elsworth ${ }^{2}$ \\ ${ }^{1}$ Department of Petroleum Geology \& Geology, School of Geosciences, University of Aberdeen, UK \\ ${ }^{2}$ Department of Energy and Mineral Engineering, EMS Energy Institute and G3 Center, Pennsylvania State \\ University, University Park, Pennsylvania, USA \\ ${ }^{3}$ Laboratory of Coal Resources and Safe Mining (China University of Mining and Technology)
}

\begin{abstract}
Sand injectite complexes comprise kilometer-scale clastic intrusion networks that act as effective conduits for the migration, accumulation and then recovery of hydrocarbons and other fluids. An equivalent continuum model is constructed to represent a sand injectite reservoir, coupling stress and fluid flow in fractured rock using the continuum simulator TOUGHREACT coupled with FLAC3D to follow deformation and fluid flow. A permeability model, which uses staged percolation models, is proposed to improve permeability estimation of fracture networks by accommodating four different levels of fracture connectivity. This permeability model is confirmed against field and laboratory data, corresponding to the different connectivities of fracture networks. The new constitutive permeability model is incorporated into the coupled hydro-mechanical simulator framework and applied to sand injectites with the analysis of permeability evolution mechanisms and mechanical sensitivity. The results indicate that when the magnitudes of principal stresses increase in a constant ratio, normal closure is the dominant mechanism in reducing fracture aperture and thereby permeability. Conversely, the evolution of stress difference can accentuate aperture and permeability due to an increase in shear dilation for critically or near-critically oriented fractures. Also, the evolution of aperture and related permeability of fractured rock are more sensitive at lower stress states than at higher stress states due to the hyperbolic relationship between normal stress and normal closure of the fractures.
\end{abstract}


Keywords: Hydro-mechanical coupling; Fracture network connectivity; Sand injectite reservoir; Permeability evolution; Staged percolation theory; Fractured rock.

\section{Introduction}

\subsection{Geological background and significance}

Sand injectite systems are increasingly common in outcrop and subsurface studies of shallow crustal processes. They are typified by complex geometries and can accommodate commercial volumes of hydrocarbons. ${ }^{1,2}$ Such reservoirs are formed from sand, sourced from an overpressured sandstone parent unit, remobilised as a fluidised slurry and injected by hydraulic fracturing into an otherwise impermeable unit. ${ }^{3,4,5}$ One such reservoir is the Panoche Giant Injection Complex (PGIC) within the San Joaquin Basin, California. Tectonically-induced basin-scale fluid overpressures have propagated fractures upward to form fracture networks. ${ }^{6,7}$ These fracture networks typically communicate between reservoirs, sometimes separated by low permeability seals spanning hundreds of meters ${ }^{8}$ and potentially destroying seals and traps. ${ }^{9}, 10,11$

In sand injectites, fractures with a lower dip generally have greater initial lengths and apertures than fractures with a higher dip. Besides, after the sand intruded into the fractures across horizontal formations, the sand intrusions with a higher dip are relatively poorly sorted, more tightly packed with low porosity than sand intrusions with a lower dip. ${ }^{12}$ In contrast, the sand intrusions with a lower dip are usually moderately sorted and loosely packed, and with moderate porosity. These characteristics make the permeability pervasively lower for the intruded fractures with a higher dip than those with a lower dip. Overall, the average permeability of sand dikes in the PGIC is $\sim 220 \mathrm{mD}$, whereas the sand dikes of higher $\left(>40^{\circ}\right)$ and lower dips $\left(\leq 20^{\circ}\right)$ have an average permeability of $\sim 81 \mathrm{mD}$ and $\sim 529 \mathrm{mD}$, respectively. ${ }^{12}$

Sand injectites are unique in which small-scale vertical permeability often exceeds horizontal permeability, making thin pay zones very productive. ${ }^{13}$ Basin-scale sand injectite complexes can significantly change fluid migration routes and fluid flow behaviors. Hydraulic fractures and sand dikes may dramatically increase field-scale vertical permeability and enable regional-scale inter-reservoir communication. ${ }^{14}$ However, 
such positive effects of improved access to hydrocarbons may be offset by deleterious impacts of early water breakthrough. ${ }^{15}$ Therefore, it is important to investigate and improve the estimation of fluid flow behaviors within fractured reservoirs.

Each set of the intruded dykes / fractures are intersected with each other at particular orientations. Due to the shallow sedimentary lithology formation including unconsolidated and consolidated layers, it is very essential to develop a new permeability model, which includes connectivity of dyke / fracture networks, with consideration of matrix permeability influence. According to the proposed permeability model developed in this work, it would be more accurate to assess the evolution of permeability of sand injectites, and predict the flow path in the dykes / fracture networks.

\subsection{Applicable permeability models}

Permeability models to represent the equivalent permeability of fractured rock originally assumed ubiquitous fractures of infinite lateral extent ${ }^{16,17}$ Such characterizations typically incorporate the cubic law ${ }^{18}$ with the presence of truncated fractures representing more reasonable estimations of permeability. ${ }^{19}$ Ignoring fluid exchanges between fractures and matri $^{20}$ renders estimated permeability lower than true permeability where matrix permeability is significant. ${ }^{21} \mathrm{~A}$ variety of approaches have refined permeability models for fractured media. ${ }^{22,23,26,27}$ For fracture networks of nested scales, fractal characteristics ${ }^{28}$ have been applied by representing fractal dimensions of multiple physical parameters, ${ }^{29}$ including the implementation of checkerboard approaches. ${ }^{30}$

None of those previously discussed references consider percolation. Nevertheless, percolation theory ${ }^{31}$ is able to determine the degree of connectivity of fracture networks. Permeability models based on percolation theory have been useful in analysing transport properties of disordered systems. ${ }^{20,24,25}$ The classical concept of percolation theory describes the percolation probability of connected clusters in a random system. The concept of percolation theory for a fractured medium makes extensive use of dimensionless density to quantify the degree of fracture connectivity and increases permeability estimation ${ }^{32}$ in both two and three dimensional fractured media with various local permeability for fractures. ${ }^{24,25,37}$ Equivalent permeability is critically controlled by fracture network connectivity ${ }^{33}$ with dimensionless densities recovered from field data, e.g. outcrops. ${ }^{34}$ 
The onset of percolation of fracture networks greatly increases the permeability of the fractured rock. This percolation threshold may be estimated theoretically based on the fracture density, length, and shape of fractures. ${ }^{35,36,37}$ With fracture geometry recovered from field data and outcrops, fracture network permeability can be estimated analytically. ${ }^{32,38,39}$ Overall, after determining the dimensionless density, density, fracture distribution and percolation threshold of fractured rock, fracture network connectivity can be measured, and permeability of fractured rock may be derived based on different connectivity levels of the fracture networks - this is the approach followed later in this work.

\subsection{Coupled modeling approaches}

Fractures increase the complexity of fluid flow behavior and stress response within fractured media. To better represent the response of fractured rock, constitutive relationships which couple stress and fluid flow are crucial. For example, laboratory data and some field data have found that aperture and subsequent permeability can be at least partly controlled by in-situ stresses and fluid pressures ${ }^{28}$, and that percolation methods typically do not consider these effects. Thus, aperture model is derived as a constitutive model depending on the in-situ stresses and fluid pressures, which is then combined into percolation methods. There are two primary approaches that are widely implemented for the characterization of fractured rock, viz: discontinuum and equivalent continuum approaches. $^{40}$

Discontinuum approaches assume that the rock mass consists of individual blocks delimited by fractures. These fractures can be defined either as explicit discrete elements by matrix blocks with interfaces between them. ${ }^{41}$ The advantage of the discontinuum approach is that this approach is more suitable in evaluating small-scale response in detail and over the short term. However, the computational complexity required for modelling flow in a dual system of fractures and matrix, and the exchange between the two systems, demands more advanced software and hardware configurations, and requires more computational time. ${ }^{42}$ 
In contrast, the equivalent continuum approach seems more suitable for long term simulation of large-scale fractured rock. The major assumption of this approach is that the macroscopic behaviour of fractured rock and their constitutive relationships can be characterised by the laws of continuum mechanics. ${ }^{40}$ Fracture properties are implicitly embedded in the equivalent continuum model and included in modulus parameters.

In the work presented here, the continuum simulator TOUGHREACT ${ }^{43}$ is used to couple fluid flow with deformation response of the rock mass represented by the code in FLAC3D. ${ }^{44}$ Constitutive models used in the simulator represent the coupled mechanical deformation and poroelastic response of the fractured rock, and characterize aperture and permeability evolution. ${ }^{45}$

Based on the constitutive models, the workflow of the equivalent continuum simulation begins with equilibration of temperature and pore fluid pressure in TOUGHREACT. Then the fracture information, such as fracture geometries and modulus, is input into a FORTRAN executable. The composite fracture modulus with the equilibrium pore fluid pressure are input into FLAC3D to perform the stress-strain simulation. Then the revised pore fluid pressure field is redistributed based on the dual porosity poromechanics. ${ }^{40,43}$ The stress-induced permeability is investigated through two-way implicit coupling in the code. The effective stress state of fractures is updated dynamically. Based on the effective stress state, the fracture aperture will be calculated accordingly. Due to the modification of fracture aperture, the composite modulus of fractured block is also updated simultaneously. The two-way coupling could reflect the influence of mechanical properties evolution in changing pore pressure distribution and flow path.

\subsection{Aims and objectives}

Regionally-developed giant sand injectite systems affect subsurface hydrocarbon volume and significantly influence fluid migration paths by coupling hydro-mechanical processes. The big research picture is reservoir characterization of sand injectites, which includes three stages: 1. Estimate the permeability of the fracture / dike networks in sand injectites; 2. Model fracture propagation; 3. Characterise sand intrusion. This paper will focus on the fluid transport properties of fracture networks assuming no fracture 
propagation and before the onset of sand intrusion, which is the first stage for the research of reservoir characterization of the sand injectites. Hence, the implemented assumptions and theory will be related to the permeability estimation of fractured rocks with the background of sand injectites, before coupling fracture propagation and sand intrusion in the future.

\section{Permeability Models}

A model for fractured sand injectite systems is developed as an equivalent continuum model. This equivalent continuum model couples stress and fluid flow, and links constitutive relationships including fracture aperture, porosity and permeability as key elements. The concept of percolation theory is implemented to estimate the permeability of the fractured reservoir where the fracture network connectivity is classified by the degrees of percolation represented by dimensionless density. The permeability model is confirmed by comparing its permeability magnitude against field and laboratory data. Besides, the proposed permeability model, which is based on percolation theory, enables us to account for the fracture connectivity, network percolation and fluid exchange between fractures and matrix. These are essential in simulating fluid flow and permeability evolution and to improve the accuracy of permeability estimation of sand injectites. Finally, the permeability model is incorporated into the simulator framework and applied to represent the response of sand injectites via permeability evolution mechanisms and mechanical sensitivity.

\subsection{Stress coupling}

A cornerstone of the analysis is representing changes in fracture apertures as driven by mechanical states and then relating this to permeability. The permeability calculations which will be discussed in the later sections is derived using aperture. As aperture is stress-dependent and updated by stress evolution in each simulation loop, permeability is then regarded as stress-dependent as well, updated with the stress change in each loop. The change in aperture is captured in Eq. (1). ${ }^{40,47}$ 
$b=b_{i n i}-\frac{9 b_{i n i} S_{n}^{\prime}}{S_{n c}+10 S_{n}^{\prime}}+\frac{\tau-\tau_{s c}}{K_{s}} \tan \phi_{d}+\frac{P_{f}-P_{f 0}}{10 \times \frac{7 \pi}{24} \frac{G}{r}}$

where the final three terms refer to the magnitude of aperture change induced by normal closure, shear dilation and fracture normal opening, respectively. In this, $b$ is the resulting fracture aperture, $b_{i n i}$ is the initial aperture prior to the application of principal stresses and is determined by the expression of, ${ }^{21}$

$b_{i n i}=1.25 \times 10^{-5} l^{0.8}$

where $l$ is the fracture length. $S_{n}^{\prime}$ is the effective normal stress, $S_{n c}$ is the critical normal stress which corresponds to the maximum aperture closure, $K_{s}$ is the critical shear stiffness of fracture, $\phi_{d}$ is fracture dilation angle, $\tau$ is the fracture shear stress, $\tau_{s c}$ is the critical shear stress as equivalent to the fracture shear stress when shear failure is triggered. $\left(P_{f}-P_{f 0}\right)$ is the pore fluid pressure increase after tensile opening, $G$ is the shear modulus of the intact rock and $r$ is the fracture half length.

The reasons to use Eq. (1) are that it combines the magnitudes of aperture normal closure, shear dilation, and fracture opening to reflect the stress effects on aperture evolution. Also, as fracture length evolution is not considered here, length-aperture scaling model is not applied here.

\subsection{Geometric network coupling}

The estimation of permeability in fractured rock is based on multiple parameters. These include fracture aperture, length, fracture density and connectivity of the fracture networks as the primary components. One method for evaluating permeability is using the cubic law ${ }^{18}$ ( $k=\frac{w b^{3}}{12 A}$ where $b$ is aperture, $A$ is cross-sectional area of fracture, and $w$ is the fracture width), where stress-dependent aperture defined in Eq. (1) may be directly correlated with fracture permeability. However, the traditional cubic law method concerns itself only with an aperture - transmissibility / permeability relationship for a 
single fracture. Aside from aperture, the primary controlling parameter in estimating permeability of fractured systems is connectivity, measured by fracture network properties such as fracture geometry distribution, density, length.

Fracture density may be defined as,

$\rho=\frac{N_{f}}{V}$

where $N_{f}$ is the number of fractures truncating within an element, and $V$ is the element volume.

Dimensionless fracture density $\rho^{\prime}$ is a parameter which is used extensively to quantify connectivity of fracture networks. Dimensionless density $\rho^{\prime}$ can be defined by using the excluded volume $V_{e x}$, which is defined as the surrounding volume into which the center of another object may not enter if overlap is to be avoided. ${ }^{32}$

For a wide spectrum of fracture geometries, the expression of excluded volume is defined as, ${ }^{48}$

$V_{e x}=\frac{4 \pi \sum R^{3}\langle\langle\sin \gamma\rangle\rangle}{N_{f}}$.

where $A$ is the fracture area; $P$ is the fracture perimeter; $R$ is the fracture half length; $N_{f}$ is the number of fractures; $\gamma_{i j}$ is the angle between the two fracture families; $\langle\langle\sin \gamma\rangle\rangle=\sum f_{i} f_{j} \sin \gamma_{i j}$ in which $f$ is the fraction of fracture family $i$ and $j$.

After the excluded volume is obtained, the dimensionless density $\rho$ for networks consist of disc-shaped fractures is defined as, ${ }^{37}$

$\rho^{\prime}=\rho V_{e x}=\frac{4 \pi}{V} \sum R^{3}\langle\langle\sin \gamma\rangle\rangle$.

If an element does not contain any fractures, then $\rho^{\prime}=0$. When the fractures form percolated paths, percolation threshold $\rho_{c}{ }^{\prime}$ of fracture networks can be theoretically 
estimated. Percolation threshold of anisotropic and heterogeneous networks (e.g. where the fracture orientations are arranged in several discrete families) do not strongly differ from those of isotropic and uniform networks. Hence, as an analytical approximation derived from a large number of numerical simulations, the percolation threshold $\left(\rho_{c}^{\prime}=2.29\right)$ for isotropic and uniform networks consist of disc-shaped fractures is applied as an approximation for anisotropic and heterogeneous model. ${ }^{65}$

Therefore, when $\rho^{\prime}<\rho_{c}^{\prime}=2.29$, the fracture network is non-percolated, whereas when $\rho^{\prime} \geq \rho_{c}^{\prime}=2.29$, the network is percolated with a preferential flow path through two opposite sides of the medium. When the fracture network is percolated, as permeability scales with the fracture aperture via a square relationship, a small aperture change can give rise to a significant permeability change. ${ }^{46}$ And permeability of the percolated fractured rock increases with an increase in fracture density and length.

Based on the degree of connectivity of fracture networks, quantified by dimensionless density, we propose a permeability model subdivided into four connectivity levels [e.g. Fig. 1 and Fig. 2], based on a wide range of rigorous numerical studies, in which results match between numerical and analytical models for each connectivity level. The classification are non-percolating range $\left(0 \leq \rho^{\prime}<2.29\right)$, low percolation range $\left(2.29 \leq \rho^{\prime}<4\right)$, moderate percolation range $\left(4 \leq \rho^{\prime}<20\right)$, and highly percolation range $\left(\rho^{\prime} \geq 20\right){ }^{24,32,39}$ Each connectivity range corresponds to a different permeability relation to provide the optimal estimates of realistic behaviours of fluid flow in fractured rock.

\subsubsection{Non-percolating range $\left(0 \leq \rho^{\prime}<2.29\right)$}

This range corresponds to non-percolated fractured systems, where fractures are isolated or spread in small disconnected clusters. Although the rock matrix has a relatively low permeability, it still contributes to the flow. Consequently, the matrix may significantly control the magnitude of permeability before percolation initiates, with the matrix permeability representing the permeability of the ensemble fractured system.

The derivation for equivalent permeability $K_{\text {equ }}$ is based on an implicit equation which accounts for the hydraulic influence between fractures, formulated as, ${ }^{63}$ 


$$
K_{\text {equ }}-K_{m}=\frac{32}{9} K_{\text {equ }} \sum_{i=1}^{n} \frac{\varepsilon_{i}}{\frac{4 K_{\text {equ }}}{\pi \alpha K_{f, i}}+1}
$$

where $\alpha=\frac{b}{2 R_{i}}, \varepsilon_{i}=\rho_{i} R_{i}^{3}$.

For fractured systems well below the percolation threshold with a low fracture density, Eq. () assumes that the magnitude of equivalent permeability is similar to the matrix permeability. The matrix permeability dominates fluid flow across the fractured rock because the fluid has to cross the rock almost through the matrix, with only local flow disturbance between the fracture and matrix near the sparse fractures. Hence, the intrinsic fracture permeability $\left(K_{f, i}=\frac{b^{2}}{12}\right)$ alone is not appropriate to characterize the permeability of this type of fractured system. Another implicit assumption is that the fracture permeability is much larger than matrix permeability ( $K_{\text {equ }} \approx K_{m} \ll K_{f, i}$ ), approximating the term $\frac{4 K_{\text {eff }}}{\pi \alpha K_{f, i}}$ to zero. Also, some in-situ tests for the rock mass with a low dimensionless density have demonstrated that although the rock mass is not a strictly homogeneous isotropic fractured medium, if a spherical radial flow is assumed, a fairly good estimate of water flow can be given. Hence, it appears to be sound to assume this type of rock mass as a continuous medium without much anisotropy in relatively large scale measurements when the matrix permeability is assumed to be isotropic. ${ }^{53}$

Therefore, the equivalent permeability of fractured rock mass with a low dimensionless density is formulated as, ${ }^{62}$

$$
\begin{gathered}
K_{\text {equ }}=\frac{K_{m}}{1-\frac{32 \sum_{i=1}^{N_{f}} \varepsilon_{i}}{9}} \\
\left(K_{\text {equ }} \approx K_{\text {ave }}\right)
\end{gathered}
$$


where isotropic equivalent permeability is assumed in this low dimensionless density range when the matrix permeability is assumed to be isotropic. $\varepsilon_{i}=\rho_{i} R_{i}^{3}$ for the $i$ th fracture and $N_{f}$ is the number of fractures in the system.

\subsubsection{Low percolation range $\left(2.29 \leq \rho^{\prime}<4\right)$}

In the low percolation stage, the permeability of the facture networks begins to act as the dominant feature, with the evolution of preferential fluid flow paths. When the matrix permeability $K_{m}$ is many orders less than the permeability $K_{n}$ of the fracture networks, the fluid flow in the matrix can be sufficiently slow. ${ }^{49}$ In this way, fractures become the preferential flow paths, and the equivalent permeability $K_{\text {equ }}$ of the rock mass is primarily determined by fracture network permeability $K_{n}$. Though the fluid flow contributed from the matrix is much smaller than the contribution from the percolated fracture networks, the matrix contribution is still included in calculating $K_{\text {equ }}$ as it may be influential depending on the application, for example, in nuclear waste repositories. The lower bound of equivalent permeability is expressed in Eq. (8) when the equal sign is applied. The fluid exchanges between fracture and matrix domains will only increase $K_{\text {equ }}$; however, these fluid exchanges depend on the network geometry and hydraulic properties and those are not easy to measure ${ }^{37}$, which is a limitation. Nonetheless, based on extensive numerical simulations, the influences of the terms $K_{n}$ and $K_{m}$ can be separated when $\rho^{\prime} \geq 4.37,39$ However, as this low percolation range is very narrow with a small number of natural fractured systems falling in this range, the lower bound expression expressed by using the equal sign is implemented to obtain the conservative $K_{\text {equ }}$ of this range.

$$
K_{\text {equ }} \geq K_{n}+K_{m}
$$

There is an important and practical expression for the permeability of fracture networks with unspecified geometry distribution. ${ }^{37}$

$$
K_{n}=\left[\sum_{l}^{N} \frac{2}{3} \rho_{l}\langle A \sigma\rangle_{l}\left(\boldsymbol{\xi}_{\mathrm{ij}}-\mathbf{n}_{i} \mathbf{n}_{j}\right)\right] \times K^{\prime \prime}
$$


where $N$ is the number of fracture sets; $\rho$ is fracture spatial density; $A$ is the fracture area; $\sigma$ is the fracture conductivity which is defined as $\sigma=\frac{b^{3}}{12}$ when open fractures with parallel walls are assumed; $\langle A \sigma\rangle$ is the statistical average value of $A \sigma ; \xi_{\mathrm{ij}}$ is the Kronecker's delta; $\mathbf{n}$ is the unit normal to the fracture plane.

The decomposition of Eq. (9) split the permeability expression into two parts: the first part is the dimensional permeability tensor which is proportional to the volumetric fracture area and independent of the fracture shape; the second part $K^{\prime \prime}$ defined in Eq. (10) is a dimensionless term which accounts for the influence of the degree of connectivity of the network. ${ }^{37}$

$$
K^{\prime \prime}=\frac{\beta\left(\rho^{\prime}-\rho_{c}^{\prime}\right)^{2}}{\rho^{\prime}\left[1+\beta\left(\rho^{\prime}-\rho_{c}^{\prime}\right)\right]}
$$

As there is no $\beta$ value for disc-shaped fractures, the most close shape (hexagons) with an available value of $\beta=0.18$ is used here. Therefore, when a fractured system is in the low percolation range with $K_{n} \gg K_{m}$, the equivalent permeability of fractured systems is eventually expressed as,

$$
K_{\text {equ }}=K_{m}+\left[\pi \sum_{l}^{N} \rho_{l}\left\langle R^{2} b^{3}\right\rangle_{l}\left(\boldsymbol{\xi}_{\mathbf{i j}}-\mathbf{n}_{i} \mathbf{n}_{j}\right)\right] \times \frac{\left(\rho^{\prime}-2.29\right)^{2}}{\rho^{\prime}\left[100+18\left(\rho^{\prime}-2.29\right)\right]}
$$

\subsubsection{Moderate percolation range $\left(4 \leq \rho^{\prime}<20\right)$}

When $\rho^{\prime} \geq 4$, more than $98 \%$ of the fractures are connected to the percolating fracture clusters. ${ }^{50}$ To quantify the dimensionless term $K^{\prime \prime \prime}$ which describe the influence of the degree of connectivity of the fracture networks of moderate and high percolation ranges, a ratio $\omega^{39}$ is introduced and revised assuming disc-shaped and open fractures with parallel walls, 


$$
\omega=\frac{1-K^{\prime \prime \prime}}{1-\frac{0.18\left(\rho^{\prime}-2.29\right)^{2}}{\rho^{\prime}\left[1+0.18\left(\rho^{\prime}-2.29\right)\right]}} .
$$

With a large number of numerical analysis, Eq. (12) is approximated as a single curve formulate when $\rho \geq 4$, which can be approximated as a heuristic and successful model (Eq. (13)), where fluid exchange is expressed by $\frac{7}{3} \sigma^{(-0.7)}$.

$$
\omega \approx \frac{1}{1+\frac{7}{3} \sigma^{(-0.7)}}
$$

where $\sigma^{\prime}=\frac{b^{3}}{12 K_{m} R_{\max }}$.

Combining Eq. (12) with Eq. (13) gives $K^{\prime \prime}$ as,

$$
K^{\prime \prime \prime}=1-\frac{1-\frac{0.18\left(\rho^{\prime}-2.29\right)^{2}}{\rho^{\prime}\left[1+0.18\left(\rho^{\prime}-2.29\right)\right]}}{1+\frac{7}{3} \sigma^{\prime(-0.7)}} .
$$

Substituting $K^{\prime \prime}$ by $K^{\prime \prime \prime}$ to account for the influence of network connectivity for moderate and high percolation ranges, the fracture network permeability $K_{n}$ which is suitable for $\rho^{\prime} \geq 4$ is expressed as, $K_{n}=\left[\sum_{l}^{N} \frac{2}{3} \rho_{l}\langle A \sigma\rangle_{l}\left(\boldsymbol{\xi}_{\mathbf{i j}}-\mathbf{n}_{i} \mathbf{n}_{j}\right)\right] \times K^{\prime \prime \prime}$.

Then incorporating Eqs. (13), ()ㅡㄹ and $\underline{(9)}$, the equivalent permeability of the fractured systems $K_{\text {equ }}$ is formulated as, 


$$
K_{e q u}=K_{m}+\frac{2}{3}\left[\pi \sum_{l}^{N} \rho_{l}\left\langle R^{2} b^{3}\right\rangle_{l}\left(\boldsymbol{\xi}_{\mathbf{i j}}-\mathbf{n}_{i} \mathbf{n}_{j}\right)\right] \times\left\{1-\frac{1}{1+\frac{7}{3} \sigma^{(-0.7)}}\left[1-\frac{0.18\left(\rho^{\prime}-2.29\right)^{2}}{\rho^{\prime}\left[1+0.18\left(\rho^{\prime}-2.29\right)\right]}\right]\right\}
$$

where $\mathrm{N}$ is the number of total fracture sets; $\xi_{\mathrm{ij}}$ is the Kronecker's delta; $\mathrm{n}$ is the unit normal to the fracture plane.

\subsubsection{High percolation range $\left(\rho^{\prime} \geq 20\left(\rho^{\prime} \gg 10\right)\right)$}

This percolation range indicates a highly percolated fractured system, and is rare in nature. Nonetheless, to cover the entire connectivity range, this range is still included.

For very dense fracture networks, the heuristic analytical expression of $K^{\prime \prime}$ is revised as, ${ }^{37}$

$$
K^{\prime \prime \prime}=\frac{\alpha\left(\rho^{\prime}-\rho_{c}^{\prime}\right)^{2}}{\left[1+\beta\left(\rho^{\prime}-\rho_{c}^{\prime}\right)\right]}
$$

where $\alpha=\frac{\frac{4}{3 P^{\prime}}}{\frac{P^{2}}{2 A^{\prime}}-\rho_{c}^{\prime}}, \beta=\frac{1}{\frac{P^{\prime 2}}{2 A^{\prime}}-\rho_{c}^{\prime}}, A^{\prime}=\pi$, and $P^{\prime}=2 \pi$ for disc-shaped fractures.

Substituting of Eq. (타) into Eq. ( $\underline{17)}, K^{\prime \prime \prime}$ is transformed as,

$$
K^{\prime \prime \prime}=\frac{\left(\rho^{\prime}-\rho_{c}^{\prime}\right)^{2}}{\rho^{\prime}\left(\rho^{\prime}-\rho_{c}^{\prime}+\frac{P^{2}}{2 A^{\prime}}\right)} \text {. }
$$

Combining Eq. (19) into Eq. (15) gives the permeability of fracture network as,

$$
K_{n}=\frac{2}{3}\left[\pi \sum_{l}^{N} \rho_{l}\left\langle R^{2} b^{3}\right\rangle_{l}\left(\boldsymbol{\xi}_{\mathrm{ij}}-\mathbf{n}_{i} \mathbf{n}_{j}\right)\right] \times\left\{1-\frac{1}{1+\frac{7}{3} \sigma^{\prime(-0.7)}}\left[1-\frac{\left(\rho^{\prime}-\rho_{c}^{\prime}\right)^{2}}{\rho^{\prime}\left(\rho^{\prime}-\rho_{c}^{\prime}+\frac{P^{\prime 2}}{2 A^{\prime}}\right)}\right\} .\right.
$$

As $\rho^{\prime} \gg \rho_{c}^{\prime}$, Eq. $(\underline{20)}$ can be approximated as, 


$$
K_{n}=\frac{2}{3}\left[\pi \sum_{l}^{N} \rho_{l}\left\langle R^{2} b^{3}\right\rangle_{l}\left(\xi_{\mathrm{ij}}-\mathbf{n}_{i} \mathbf{n}_{j}\right)\right]\left\{1-\frac{1}{1+\frac{7}{3} \sigma^{\prime(-0.7)}} \frac{P^{\prime 2}}{2 A^{\prime} \rho^{\prime}}\right\}
$$

Eventually, combining Eq. (21) and (8), the expression of the equivalent permeability of a highly percolated fractured system is formulated as,

$$
K_{\text {equ }}=K_{m}+\frac{2}{3}\left[\pi \sum_{l}^{N} \rho_{l}\left\langle R^{2} b^{3}\right\rangle_{l}\left(\boldsymbol{\xi}_{\mathrm{ij}}-\mathbf{n}_{i} \mathbf{n}_{j}\right)\right]\left(1-\frac{1}{1+\frac{7}{3} \sigma_{\max }^{(-0.7)}} \frac{2 \pi}{\rho^{\prime}}\right)
$$

\section{Confirmation of Permeability Model}

We take the models for permeability evolution of fractured rock and confirm these against observations of permeability and fracture geometry recovered from various underground research laboratories. The use of underground laboratories has the advantage of being closer to in-situ stress conditions with limited weathering compared to the surface outcrops. In-situ parameters are used in the verification, including apertures. As the magnitudes of apertures and other parameters result from in-situ stress effects at the time of measurement, permeability which is derived from those parameters demonstrates the corresponding in-situ magnitude at the measurement moment. Different from the dynamic simulation loops in which the stress states and stress-dependent parameters are updated in each loop, these verification processes are static and are similar to the calculation within one simulation loop in which the permeability is related to the stress states and stressdependent parameters of this loop.

\subsection{Non-percolating range $\left(0 \leq \rho^{\prime}<2.29\right)$}

Field and laboratory data from the Stripa Mine are used to confirm the permeability in the non-percolated range. An in situ experiment at the Stripa underground research laboratory measured the hydrologic parameters of the fractured rock mass by monitoring seepage into a ventilation drift of dimensions of $5 \mathrm{~m} \times 5 \mathrm{~m} \times 33 \mathrm{~m}$ (equivalent to a circular cross section with a radius of $2.8 \mathrm{~m}$ ) at a depth of $335 \mathrm{~m} .{ }^{51}$ Water temperature was $20^{\circ} \mathrm{C}$; matrix permeability $K_{m}$ of the Stripa Mine granite is $4.09 \times 10^{-18} \mathrm{~m}^{2}$. The 'matrix' rock selected in the test site for the matrix permeability test in the Stripa Mine was identified as uniform and consisted mainly of an even-grained granite with a granite texture. The 
selected granite was identified as homogeneous with few fractures, though it was not intended to imply the granite was totally free of fractures. The matrix permeability was tested using circulated warm water. The water flow-rate from the ring holes towards the center hole was measured at a certain overpressure in the ring holes, with and without counter-pressure at the center hole. These are approximations of the reality as unidentified fractures may influence water flow although a fairly good estimate of this water flow was obtained to derive matrix permeability. ${ }^{53}$

There is an average of 15 - 20 fractures embedded in every $5 \mathrm{~m}$ interval along the $33 \mathrm{~m}$ drift, indicating that this drift has $90-120$ fractures. Hence, it is assumed that the drift has an average of 100 fractures.

According to the in situ investigation, the fractures comprise four orientation sets. The percentage of each set of fractures is $\mathrm{f} 1=20 \%$ (set 1 ), $\mathrm{f} 2=25 \%$ (set 2), $\mathrm{f} 3=20 \%$ (set 3 ) and $\mathrm{f} 4=35 \%$ (set 4 ). ${ }^{53}$ Table 2 summarises the fracture data collected from this monitored drift. The fracture lengths are the mean values of the original lengths distribution estimated by the lognormal length distribution of each fracture family, with truncation bias corrected. ${ }^{51}$ Thus, the fractured rock is assumed to be comprised of four monodisperse families of fractures. The fracture aperture value was from in-situ injection tests at the test site using the standard assumption of smooth parallel fractures walls. The apertures were log-normal distributed with a computed mean of 8.3 micrometers and a standard deviation of 5.7 micrometers. ${ }^{64}$ Due to a lack of more detailed aperture information, the mean in-situ fracture aperture ( $b=8.3$ micrometers) is applied.

To calculate dimensionless density of this case, first,

$\langle\langle\sin \gamma\rangle\rangle=\sum f_{i} f_{j} \sin \gamma_{i j}=0.67$

Then, the dimensionless density of this fractured rock sample is derived as (Eq. (5)), $\rho^{\prime}=\rho V_{e x}=\frac{4 \pi}{V} \sum R^{3}\langle\langle\sin \gamma\rangle\rangle=0.73$

Permeability can be calculated from Snow's model, Oda's model and the applied model as shown below. Then the permeability results from the three models are compared with the laboratory results. 
(1) Snow's model ${ }^{16}$

One form of Snow's model for permeability tensor can be expressed as,

$k_{i j}=\sum_{j=1}^{n} \frac{b_{j}^{3}}{12 s_{j}}\left(\xi_{\mathrm{ij}}-\mathbf{n}_{i} \mathbf{n}_{j}\right)$

where $k_{i j}$ is the permeability tensor in the $i=x, y, z$ and $j=x, y, z$ directions; $n$ is the number of fracture sets; $b$ is the fracture aperture and $s$ is the fracture spacing of each fracture set. And the direction component $\left(\boldsymbol{\xi}_{\mathbf{i j}}-\mathbf{n}_{i} \mathbf{n}_{j}\right)$ is calculated as,

$\left(\boldsymbol{\xi}_{\mathrm{ij}}-\mathbf{n}_{i} \mathbf{n}_{j}\right)=\left(\begin{array}{ccc}n_{2}^{2}+n_{3}^{2} & -n_{1} n_{2} & -n_{1} n_{3} \\ -n_{1} n_{2} & n_{1}^{2}+n_{3}^{2} & -n_{2} n_{3} \\ -n_{1} n_{3} & -n_{2} n_{3} & n_{1}^{2}+n_{2}^{2}\end{array}\right)$

where $n_{1,2,3}$ is the unit normal to the fracture plane in the $x, y$ and $z$ directions, respectively.

$$
\begin{aligned}
& n_{1}=\cos \left(90^{\circ}-\text { dip }\right) \sin \left(\text { strike }-90^{\circ}\right) \\
& n_{2}=\cos \left(90^{\circ}-\text { dip }\right) \cos \left(\text { strike }-90^{\circ}\right) \\
& n_{3}=-\sin \left(90^{\circ}-\text { dip }\right)
\end{aligned}
$$

Then permeability tensor are calculated following,

$k_{11}=\frac{b^{3}}{12} \sum_{i=1}^{4} \frac{\left(n_{2}^{2}+n_{3}^{2}\right)_{i}}{s_{i}}, k_{22}=\frac{b^{3}}{12} \sum_{i=1}^{4} \frac{\left(n_{1}^{2}+n_{3}^{2}\right)_{i}}{s_{i}}, k_{33}=\frac{b^{3}}{12} \sum_{i=1}^{4} \frac{\left(n_{1}^{2}+n_{2}^{2}\right)_{i}}{s_{i}}$

Finally, the average permeability is calculated as,

$k_{\text {ave }}=\left(k_{11}+k_{22}+k_{33}\right) / 3=2.26 \times 10^{-16} \mathrm{~m}^{2}$

(2) Oda's model ${ }^{19}$

The permeability tensor $k_{i j}$ is defined as,

$k_{i j}=\sum^{N_{f}} \frac{1}{12}\left(P_{k k} \xi_{\mathrm{ij}}-P_{i j}\right)$ 
where $N_{f}$ is the number of fractures, $P_{i j}=\frac{\pi}{4} \rho \sum_{m=1}^{m=N_{f}}\left(l^{2} b^{3} n_{i} n_{j} f\right)_{m}, P_{k k}=P_{11}+P_{22}+P_{33}$, and $f$ is the fraction of the unit normal to the fractures.

Then permeability tensor can be are calculated following,

$k_{11}=\sum^{N_{f}} \frac{1}{12}\left(P_{22}+P_{33}\right), k_{22}=\sum^{N_{f}} \frac{1}{12}\left(P_{11}+P_{33}\right), k_{33}=\sum^{N_{f}} \frac{1}{12}\left(P_{11}+P_{22}\right)$

Thus, the average permeability is calculated as,

$k_{\text {ave }}=\left(k_{11}+k_{22}+k_{33}\right) / 3=1.82 \times 10^{-16} \mathrm{~m}^{2}$

(3) The applied model

The model is expressed as (Eq. (7)):

$$
K_{e q u}=\frac{K_{m}}{1-\frac{32 \sum_{i=1}^{N_{f}} \varepsilon_{i}}{9}}
$$

$\left(K_{\text {equ }} \approx K_{\text {ave }}\right)$

where $\sum_{i=1}^{N_{f}} \varepsilon_{i}=\rho_{1} R_{1}^{3}+\rho_{2} R_{2}^{3}+\rho_{3} R_{3}^{3}+\rho_{4} R_{4}^{3}=0.064$

Thus the equivalent permeability of the fractured rock mass is calculated as $5.31 \times 10^{-18} \mathrm{~m}^{2}$.

Table $\underline{3}$ shows the accuracy of this model in estimating equivalent permeability, by comparing against other models.

Taking the in situ laboratory results as a reference, the proposed model yields the closest estimations of permeability with the least errors (Table $\underline{3}$ ). This comparison confirms the proposed model in improving the estimation of permeability for fractured rock.

\subsection{Low percolation range $\left(2.29 \leq \rho^{\prime}<4\right)$}


Field and laboratory data from the Fanay Augeres uranium granite mine in France is used to confirm the permeability model in this low percolation range. This mine consists of a complex series of excavations which extend from $40 \mathrm{~m}$ to $320 \mathrm{~m}$ in depth over an area of around $20 \mathrm{~km}^{2}$. The dimensions of the monitored drift is $3 \mathrm{~m}$ in diameter $(\mathrm{D}=3 \mathrm{~m})$ and $80 \mathrm{~m}$ in length $(\mathrm{L}=80 \mathrm{~m})$. Thus, the drift volume $V$ for a cylindrical cavity is $\sim 565 \mathrm{~m}^{3}$.

Permeability estimates are based on in situ hydraulic tests. The matrix permeability of the granite $K_{m}$ is $\sim 4 \times 10^{-23} \mathrm{~m}^{2}$. An estimate of the in-situ apertures which were lognormal distributed for each fracture set was made by assuming that the apertures of fractures intersecting a well test zone were proportional to the fracture opening observed in the core. The trace lengths which were lognormal distributed were recorded as well as the location distribution of the center of observable trace. The mean fracture length and aperture were used as the means of the length and aperture distributions, respectively, for each fracture set from geostatistical analysis with censoring error corrected. ${ }^{56} \mathrm{Gros}^{54}$ identified five major sets of fractures by their orientations (Fig. 4).

Under the assumption that the fractures were sufficiently open, hydraulic tests with packers were performed. Parameters for the conductive fractures are summarised in Table 4.

Then $\langle\langle\sin \gamma\rangle\rangle$ is calculated as,

$\langle\langle\sin \gamma\rangle\rangle=\sum f_{i} f_{j} \sin \gamma_{i j}=0.61$

Then, the dimensionless density is derived as, ${ }^{67}$

$\rho^{\prime}=\rho V_{e x}=\frac{4 \pi}{V} \sum R^{3}\langle\langle\sin \gamma\rangle\rangle=2.92$

Similar to the previous confirmation case, Snow's model, Oda's model and the applied model are implemented here for results comparison.

(1) Snow's model ${ }^{16}$

As fracture spacing data was not available for this rock mass, another form of Snow's model which does not include fracture spacing term is applied and shown as, 
$k_{i j}=\sum_{m}^{N_{f}}(\rho A \sigma)_{m}\left(\boldsymbol{\xi}_{\mathbf{i j}}-\mathbf{n}_{i} \mathbf{n}_{j}\right)_{m}$

where $N_{f}$ is the number of fractures; $A$ is the fracture plane area; $\sigma$ is the fracture conductivity; $\rho$ is the fracture density.

Then the permeability calculation follows,

$k_{11}=\sum_{m}^{N_{f}}(\rho A \sigma)_{m}\left(n_{2}^{2}+n_{3}^{2}\right)_{m}, k_{22}=\sum_{m}^{N_{f}}(\rho A \sigma)_{m}\left(n_{1}^{2}+n_{3}^{2}\right)_{m}, k_{33}=\sum_{m}^{N_{f}}(\rho A \sigma)_{m}\left(n_{1}^{2}+n_{2}^{2}\right)_{m}$.

And the average permeability is calculated as,

$k_{\text {ave }}=\left(k_{11}+k_{22}+k_{33}\right) / 3=2.3 \times 10^{-9} \mathrm{~m}^{2}$

(2) Oda's model ${ }^{19}$

The permeability tensor $k_{i j}$ is defined as,

$k_{i j}=\sum^{N_{f}} \frac{1}{12}\left(P_{k k} \xi_{\mathrm{ij}}-P_{i j}\right)$

where $N_{f}$ is the number of fractures, $P_{i j}=\frac{\pi}{4} \rho \sum_{m=1}^{m=N_{f}}\left(l^{2} b^{3} n_{i} n_{j} f\right)_{m}, P_{k k}=P_{11}+P_{22}+P_{33}$, and $f$ is the fraction of the unit normal to the fractures.

Then permeability tensor can be are calculated following,

$k_{11}=\sum^{N_{f}} \frac{1}{12}\left(P_{22}+P_{33}\right), k_{22}=\sum^{N_{f}} \frac{1}{12}\left(P_{11}+P_{33}\right), k_{33}=\sum^{N_{f}} \frac{1}{12}\left(P_{11}+P_{22}\right)$

Thus, the average permeability is calculated as,

$k_{\text {ave }}=\left(k_{11}+k_{22}+k_{33}\right) / 3=2.14 \times 10^{-9} m^{2}$

(3) The applied model

The model is expressed as (Eq. (11)), 
$K_{e q u}=K_{m}+\left[\pi \sum^{N_{f}} \rho\left\langle R^{2} b^{3}\right\rangle\right]\left(\boldsymbol{\xi}_{\mathrm{ij}}-\mathbf{n}_{i} \mathbf{n}_{j}\right) \times \frac{\left(\rho^{\prime}-2.29\right)^{2}}{\rho^{\prime}\left[100+18\left(\rho^{\prime}-2.29\right)\right]}$

where $\left\langle R^{2} b^{3}\right\rangle$ is the average of $R^{2} b^{3} . N_{f}$ is the number of fractures. $R$ is the fracture half length. $b$ is fracture aperture. $\rho^{\prime}=2.92$.

The permeability can be calculated as,

$k_{11}=5.02 \times 10^{-14} \mathrm{~m}^{2}, k_{22}=3.35 \times 10^{-14} \mathrm{~m}^{2}, k_{33}=3.97 \times 10^{-14} \mathrm{~m}^{2}$

The average permeability is obtained as,

$k_{\text {ave }}=\left(k_{11}+k_{22}+k_{33}\right) / 3=4.11 \times 10^{-14} \mathrm{~m}^{2}$

Table 5 shows the accuracy of this model in estimating equivalent permeability, by comparing against other models.

Therefore, taking the in situ laboratory results as a reference, the proposed model is confirmed by rendering the relatively most reasonable estimates of permeability of fractured rock falling in this connectivity range, with the least errors when compared with Snow's and Oda's models.

\subsection{Moderate to high percolation range $\left(4 \leq \rho^{\prime}<20\right)$}

Data from a fractured Hercynian granite in La Peyratte, France is used for confirmation in this connectivity range. This granite sample is fine grained and crosscut by numerous fractures. A granite sample $52 \mathrm{~cm} \times 35 \mathrm{~cm} \times 36 \mathrm{~cm}$ was sawn into nine parallel prisms of identical thickness of $4 \mathrm{~cm}$ each. Nine trace maps were drawn from the nine prismatic samples (Fig. 5) with each fracture trace in each plate labeled, and traces from the same fracture were labeled identically. ${ }^{56}$ Fracture patterns were primarily composed of two families oriented at about $\pm 30^{\circ}$ from the vertical (y-) direction.

From the previous measurements, parameters necessary to estimate the equivalent permeability of the fractured rock are summarised as below and in the Table 6 . 
The volume of the sample was $V=65520 \mathrm{~cm}^{3}$; the sample contained $N_{f}=90$ fractures; the total fracture area was measured as $S=2.05 \mathrm{~m}^{2}$, corresponding to an average fracture length $l=0.17 \mathrm{~m}$; the average aperture was measured as $b=2.5 \times 10^{-6} \mathrm{~m}$. Due to the absence of enough information, this mean fracture aperture value will be applied. The matrix permeability $K_{m}$ was measured as $\sim 9 \times 10^{-18} \mathrm{~m}^{2}$. In this case, the fracture networks contribute overwhelmingly to fluid flow and the fracture network permeability is primarily calculated.

From these parameters, fracture spatial density is evaluated as $\rho=1364 \mathrm{~m}^{-3}$.

Then $\langle\langle\sin \gamma\rangle\rangle$ can be calculated as,

$\langle\langle\sin \gamma\rangle\rangle=\sum f_{i} f_{j} \sin \gamma_{i j}=0.36$

Using these above parameters, the excluded volume is calculated as,

$V_{e x}=4 \pi \frac{\sum(l / 2)^{3}}{N_{f}}\langle\langle\sin \gamma\rangle\rangle=0.0072 \mathrm{~m}^{3}$

Hence, the dimensionless density is derived as,

$\rho^{\prime}=\rho V_{e x}=4 \pi \rho \frac{\sum_{i=1}^{N_{f}}(l / 2)^{3}}{N_{f}}\langle\langle\sin \gamma\rangle\rangle=9.8$

Next, Snow's model, Oda's model and the applied model are adopted to calculate the permeability of this fractured rock, respectively.

(1) Snow's model ${ }^{16}$

According to the available data, the formulae of Snow's model is, $k_{i j}=\sum_{m}^{N_{f}}(\rho A \sigma)_{m}\left(\boldsymbol{\xi}_{\mathbf{i j}}-\mathbf{n}_{i} \mathbf{n}_{j}\right)_{m}$

where $N_{f}$ is the number of fractures; $A$ is the fracture plane area; $\sigma$ is the fracture conductivity; $\rho$ is the fracture density. 
Then the permeability is calculated as,

$$
\begin{aligned}
& k_{11}=\sum_{m}^{N_{f}}(\rho A \sigma)_{m}\left(n_{2}^{2}+n_{3}^{2}\right)_{m}=3.38 \times 10^{-15} \mathrm{~m}^{2} \\
& k_{22}=\sum_{m}^{N_{f}}(\rho A \sigma)_{m}\left(n_{1}^{2}+n_{3}^{2}\right)_{m}=3.12 \times 10^{-15} \mathrm{~m}^{2} \\
& k_{33}=\sum_{m}^{N_{f}}(\rho A \sigma)_{m}\left(n_{1}^{2}+n_{2}^{2}\right)_{m}=0.9 \times 10^{-15} \mathrm{~m}^{2}
\end{aligned}
$$

And the average permeability is calculated as,

$$
k_{\text {ave }}=\left(k_{11}+k_{22}+k_{33}\right) / 3=2.47 \times 10^{-15} \mathrm{~m}^{2}
$$

\section{(2) Oda's model ${ }^{19}$}

The permeability tensor $k_{i j}$ is defined as,

$$
k_{i j}=\sum^{N_{f}} \frac{1}{12}\left(P_{k k} \xi_{\mathrm{ij}}-P_{i j}\right)
$$

where $N_{f}$ is the number of fractures, $P_{i j}=\frac{\pi}{4} \rho \sum_{m=1}^{m=N_{f}}\left(l^{2} b^{3} n_{i} n_{j} f\right)_{m}, P_{k k}=P_{11}+P_{22}+P_{33}$, and $f$ is the fraction of the unit normal to the fractures.

Then permeability tensor can be are calculated following,

$$
\begin{aligned}
& k_{11}=\sum^{N_{f}} \frac{1}{12}\left(P_{22}+P_{33}\right)=1.78 \times 10^{-15} \mathrm{~m}^{2} \\
& k_{22}=\sum^{N_{f}} \frac{1}{12}\left(P_{11}+P_{33}\right)=1.69 \times 10^{-15} \mathrm{~m}^{2} \\
& k_{33}=\sum \frac{1}{12}\left(P_{11}+P_{22}\right)=0.48 \times 10^{-15} \mathrm{~m}^{2} .
\end{aligned}
$$

Thus, the average permeability is calculated as, 
$k_{\text {ave }}=\left(k_{11}+k_{22}+k_{33}\right) / 3=1.32 \times 10^{-15} \mathrm{~m}^{2}$

(3) The applied model

The model is expressed as (Eq. (16)),

$$
K_{e q u}=K_{m}+\frac{2}{3}\left[\pi \sum_{l}^{N} \rho_{l}\left\langle R^{2} b^{3}\right\rangle_{l}\left(\boldsymbol{\xi}_{\mathrm{ij}}-\mathbf{n}_{i} \mathbf{n}_{j}\right)\right] \times\left\{1-\frac{1}{1+\frac{7}{3} \sigma^{\prime(-0.7)}}\left[1-\frac{0.18\left(\rho^{\prime}-2.29\right)^{2}}{\rho^{\prime}\left[1+0.18\left(\rho^{\prime}-2.29\right)\right.}\right]\right\}
$$

where $\left\langle R^{2} b^{3}\right\rangle$ is the average of $R^{2} b^{3} . N_{f}$ is the number of fractures. $R$ is the fracture half length. $b$ is fracture aperture. $\sigma^{\prime}=\frac{b^{3}}{12 K_{m} R_{\max }}$. Dimensionless density $\rho^{\prime}=9.8$.

The permeability can be calculated as,

$k_{11}=2.18 \times 10^{-17} \mathrm{~m}^{2}, k_{22}=2.02 \times 10^{-17} \mathrm{~m}^{2}, k_{33}=0.58 \times 10^{-17} \mathrm{~m}^{2}$.

The average permeability is obtained as,

$k_{\text {ave }}=\left(k_{11}+k_{22}+k_{33}\right) / 3=1.59 \times 10^{-17} \mathrm{~m}^{2}$

Table 7 shows the accuracy of this model in estimating equivalent permeability, by comparing against other models.

Therefore, compared with the reference permeability, the applied model is confirmed by providing the relatively closest estimate of permeability of fractured rock of this connectivity range, when compared with Snow's and Oda's models.

\section{Application in Sand Injectite Systems}

In contrast to homogeneous permeability systems, fracture patterns in sand injectite systems may form heterogeneous fluid flow behaviors, which lead to heterogeneous fluid flow behaviors with preferential fluid migration paths. These fracture patterns makes sand injectites a heterogeneous permeability system, facilitating the migration of fluid throughout the reservoir, redistributing pore pressure fields, and influencing the evolution of aperture and thereby permeability. 
At the current research stage which is the first step for the reservoir characterization of the sand injectites, it aims to estimate the permeability of the fractured sand injectites. A static geological model is first constructed based on the targeted PGIC outcrops, which is then incorporated into the constitutive simulator framework. Thereafter, the proposed permeability model is applied to the sand injectites, followed by some analysis of permeability evolution mechanisms before coupling fracture propagation and sand intrusion in the future.

\subsection{Model setting}

From the PGIC outcrop, the thickness of the mudstone caprock is $\sim 476 \mathrm{~m}$, overlaying the $\sim 224 \mathrm{~m}$ thick sandstone formation. Fracture networks are developed in the mudstone when the pore fluid pressure builds up in the sandstone parent unit to a value where fracturing of the overburden mudstone occurs. ${ }^{58}$ The fracture networks consist of two sets of fractures which are oriented at approximately $-20^{\circ}$ (below) and $+70^{\circ}$ (above) the horizontal (Fig. $\underline{6}$ ). The average length of the sub-horizontal fracture set (set 1) is larger than the sub-vertical fracture set (set 2). The fractures are assumed as disc-shaped, and the percolation threshold $\left(\rho_{c}^{\prime}=2.29\right.$ ) discussed in section 2.2 is used. ${ }^{65}$ The initial apertures are determined from the initial fracture lengths (Eq. (2)). ${ }^{21}$ Fracture propagation is not considered at the current stage while apertures are updated with stress states in each simulation loop. The simulation is block-wised, thus parameters like the fracture spatial density and dimensionless density are determined element by element. Hence, different elements may have different dimensionless densities. Then the selection of the permeability formulae from Table 1 for each element is determined by the dimensionless density of each element.

A reservoir model for the representation of the PGIC outcrops is constructed in which the fracture locations and lengths are transferred from the outcrops to represent the reservoir. The injection well is located at the bottom left-side of the complex (Fig. 7) within the sandstone formation at coordinates $(460,168)$. The pre-stressed fractures are in initial equilibrium under the applied boundary stresses and pore pressure. 
Initial reservoir properties are summarised in Table 8. Parameters in Table 8 and 9 are chosen to demonstrate the significance of stress-dependent behavior for aperture and permeability in the model and do not necessarily reflect the exact in situ conditions of the model. The impact of temperature in the simulator is that the temperature influences the compressibility of reservoir fluids. Isothermal injection is assumed in this work.

\subsection{Effect of applied stress}

In situ stresses have a direct impact on the potential for fracture shear failure, the evolution of stress-dependent aperture and the corresponding evolution of permeability. Two scenarios are proposed to examine the effects of different stress states and the mechanical sensitivity of the evolution of aperture and permeability (Table 9). The fracture failure criterion is based on the Mohr-Coulomb failure criterion in which fluid pressurisation initially reduces normal closure of aperture due to the reduction of the effective normal stress of the fractures. When the effective normal stress is reduced enough to touch the Coulomb failure envelope, shear failure occurs and the shear dilation magnitude in the aperture model begins to be larger than zero. The continuous fluid pressurisation keeps the fracture aperture open.

\subsubsection{Scenario one: constant stress ratio $(\mathrm{Szz} / \mathrm{Sxx}=\mathbf{0 . 8 2})$}

When the applied principal stresses increase proportionally, fracture aperture and permeability correspondingly decrease (Fig. 8 and Fig. 9a). The initial aperture is defined from the initial fracture length (Eq. (2)). When the horizontal principal stress Sxx is increased from $30 \mathrm{MPa}$ to $60 \mathrm{MPa}$, permeability of the fractured rock mass on the $115^{\text {th }}$ day is reduced to one seventh the magnitude of the permeability at $30 \mathrm{MPa}$, dropping from $\sim 7 \times 10^{-15} \mathrm{~m}^{2}$ to $\sim 1 \times 10^{-15} \mathrm{~m}^{2}$ (Fig. 9b). This is in response to normal closure of fractures, dominating the evolution of fracture permeability.

\subsubsection{Scenario two: influence of stress difference}

This scenario explores the influences of deviatoric stress on the evolution of aperture and permeability. The horizontal principal stress $(\mathrm{Sxx})$ is increased as the vertical principal stress (Szz) is held constant. Based on the Mohr-Coulomb failure criterion, the critical orientation of a fracture is calculated as, ${ }^{61}$ 
$\varphi_{\text {critical }}=90-\left(45+\frac{\varphi_{\text {friction }}}{2}\right)$

where fracture friction angle $\varphi_{\text {friction }}=27^{\circ}$ (Table 8). Hence, the critical failure orientation is derived as $\varphi_{\text {critical }}= \pm 31.5^{\circ}$ relative to the orientation of the maximum principal stress. As shear failure and dilation may result in critically or near critically oriented fractures, critical orientation can be used to judge which fracture set will preferentially dilate: only the (near) critically oriented fractures will dilate, while fractures that are far from critically-oriented are less likely to fail and are dominated by normal closure. Hence, when the maximum principal stress is horizontal, the sub-horizontal fracture set (set 1) which is oriented at $-20^{\circ}$ below the horizontal is near critically oriented. Conversely, when the maximum principal stress is vertical, the sub-vertical fracture set (set 2) which is oriented at $70^{\circ}$ is nearcritically oriented.

More discussion about the influence of stress difference will be in the next section.

For the comparison of the two fracture sets, Fig. 10a and Fig. $10 \mathrm{~b}$ demonstrate that under varying horizontal principal stresses, the sub-vertical fracture set (set 2) displays a wider aperture distribution than sub-horizontal fracture set (set 1) does. This is because fracture set (set 2) is near perpendicular to the increasing horizontal principal stress, thus the aperture is more sensitive to normal closure.

\subsection{Mechanisms for evolution of aperture and permeability}

We characterize the principal mechanisms controlling the magnitudes and rates of augmentation / reduction of fracture aperture and permeability, by examining the stress states and failure process for each set of fractures. The principal mechanisms for aperture and permeability evolution are summarised in Table 10. This table indicates that the evolution under elevated stress states may be dominated by normal closure and absent shear failure, while at elevated deviatoric stress differences the potential for fracture shear failure is increased.

As this work focuses on the fluid transport properties of fracture networks with the background of sand injectites, this work is related to some mechanisms of permeability 
evolution shown with the applied permeability model, though the the value added by the applied permeability model is discussed in previous sections.

Fig. 11 illustrates the evolution of aperture and permeability with time for the three stress states which generate normal closure but without shear failure. During the simulation, and as a result of fluid pressurisation, effective normal stresses and related normal closure decrease gradually, resulting in an increase in aperture and permeability. Reduced boundary stresses correspond to a greater evolution rate of permeability with time, due to the larger fraction of the pore pressure on the total stresses. This results in greater sensitivity to changes in aperture and permeability at lower stress states than at higher stress states, due to the non-linear relationships between normal stress and normal closure of fractures (Eq. (1)).

Conversely, Fig. 12 illustrates stress states that meet the critical conditions to trigger shear failure and shear dilation. Since the maximum principal stress is horizontal, the subhorizontal fracture set (set 1) is near-critically oriented and is more prone to fail than the sub-vertical fracture set (set 2).

Fig. 12 also demonstrates that the aperture initially closes in normal mode but then drastically increases with the onset of shear failure. Before shear failure initiates, a higher stress state induces a larger normal closure, yielding a smaller aperture and reduced permeability. However, when fracture shear failure is triggered, critically oriented fractures dilate to increase the aperture. A larger stress difference inducing a larger shear dilation. Additionally, a higher stress difference enhances the potential for fracture failure by moving the Mohr circle closer to the Coulomb failure envelope, and thereby inducing earlier shear failure. The shear dilation and permeability increase are irreversible under the constant fluid pressurisation, preserving the preferential flow paths along the failed and dilated fractures.

\section{Conclusions}

We present a systematic development, confirmation then application of a coupled hydromechanical permeability model based on percolation theory that is used to investigate the evolution mechanisms and mechanical sensitivity of permeability in fractured sand 
injectite systems. As sand injectites systems contain shallow sedimentary lithology formation which may consist of unconsolidated and consolidated layers, the permeability model that includes the connectivity of fracture networks, with consideration of matrix permeability influence would be essential to assess the evolution of permeability and predict the flow path within sand injectites.

The proposed permeability model (Table 1) is developed using staged percolation models, based on the degree of connectivity of fracture networks quantified by a dimensionless fracture density $\rho$. The implementation of staged percolation models for the permeability estimation enables reasonable characterization of different connectivity levels of fracture networks in the framework of continuum simulator. Development of different permeability relations which correspond to each connectivity range allows to provide the optimal estimates of realistic behaviours of fluid flow in fractured rock using percolation theory.

Then the permeability model is incorporated into an existing coupled hydro-mechanical simulator and applied to a sand injectite reservoir to investigate the evolution mechanisms and mechanical sensitivity of permeability. Before the onset of fracture shear failure, elevated stress states that accentuate normal closure result in reduced aperture and permeability. Aperture and permeability evolve with greater sensitivity at lower effective stress states than at higher stress states because of the hyperbolic behaviour of the normal stress and normal closure relationship of the fractures (Eq. (1) ). After the onset of shear failure, permeability evolution is dominated by first normal closure and shear dilation. Larger stress differences trigger an earlier onset of shear failure and a larger magnitude of shear dilation, which can form preferential fluid migration paths, thus, increasing the permeability at reservoir scale. Therefore, larger stress difference may significantly alter permeability anisotropy due to the larger shear dilation in critically oriented fractures: when the maximum principal stress is horizontal (e.g. thrust regime), horizontal permeability may significantly exceed vertical permeability of the fractured rock mass. Conversely, when the maximum principal stress is vertical (e.g. normal faulting), the vertical permeability of the fractured rock mass may become dominant.

\section{Acknowledgement}


The author would like to thank the financial support from the Laboratory of Coal Resources and Safe Mining (China University of Mining and Technology), the grant No. SKLCRSM16KFC01. We would also appreciate the discussion and data support from Qinghua Lei at the Imperial College London, Antonio Grippa at the University of Aberdeen, and Valeri Mourzenko at the Institut Pprime CNRS.

\section{Appendix: Figures and tables}

\section{A. Figures}

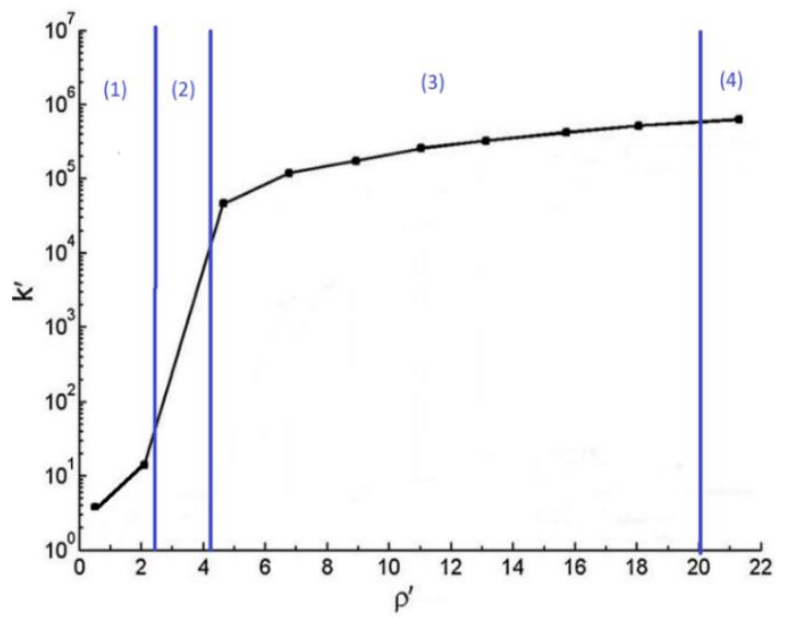

Fig. 1. Permeability changes across different connectivity levels ( $\left.\rho^{\prime}\right)$ (revised from Lang et al. ${ }^{32}$ ).

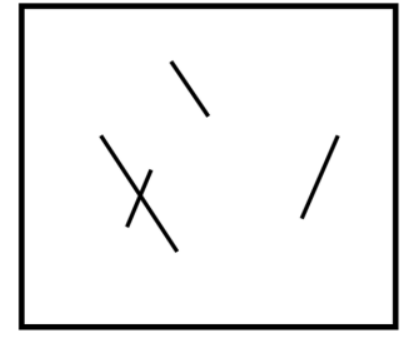

(1) $0 \leq \rho^{\prime}<2.29$

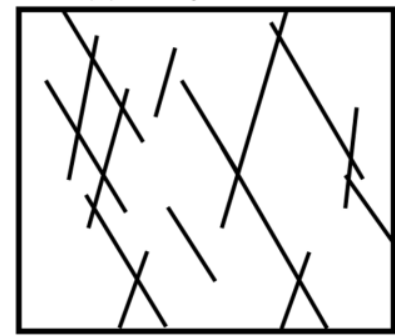

(3) $4 \leq \rho^{\prime}<20$

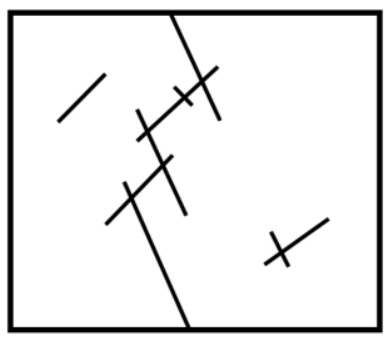

(2) $2.29 \leq \rho^{\prime}<4$

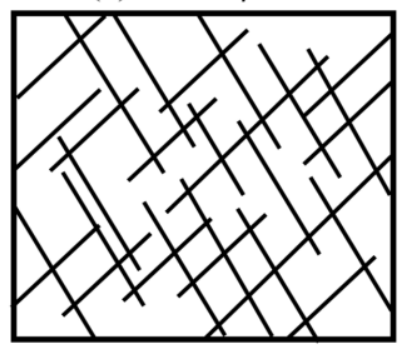

(4) $\rho^{\prime} \geq 20$ 
Fig. 2. Schematic representation of four connectivity levels of fracture networks quantified by dimensionless density $\rho^{\prime}$. (1) Non-percolating range. (2) Low percolation range. (3) Moderate percolation range. (4) High percolation range.

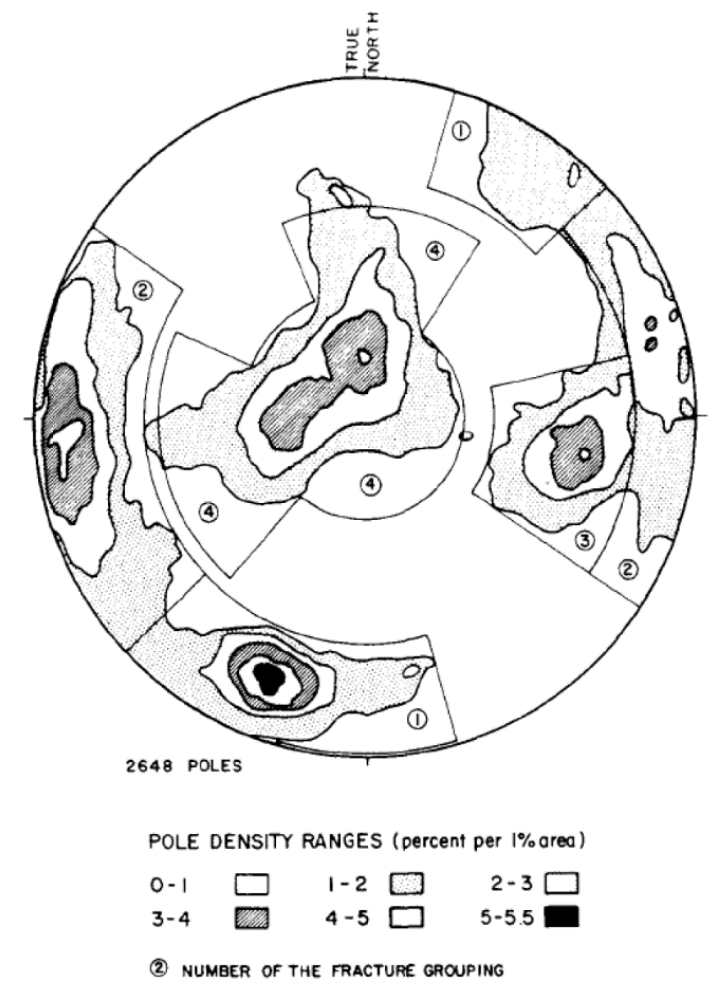

Fig. 3. Pole diagram for all the fracture planes measured in the ventilation drift. ${ }^{51}$

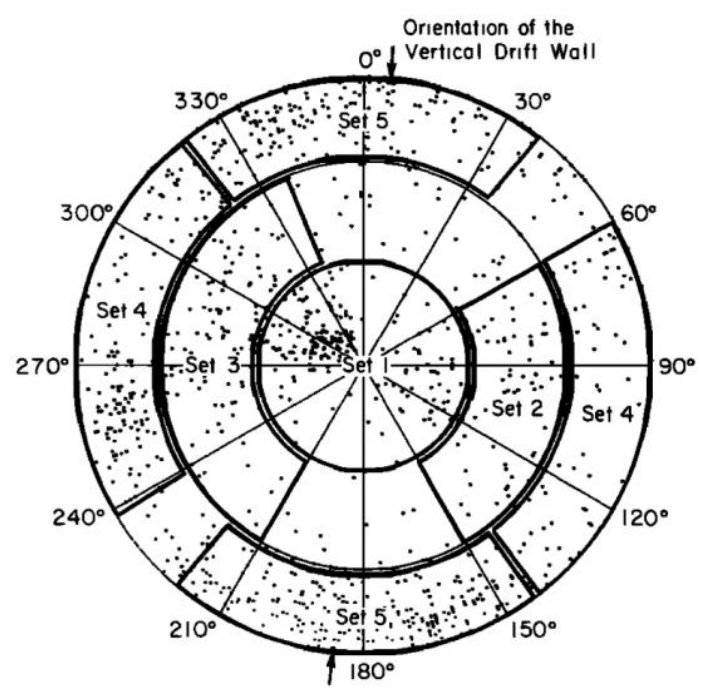

Fig. 4. Definition of sets and poles of fractures mapped in the $80 \mathrm{~m}$ section of drift wall..$^{55}$ 


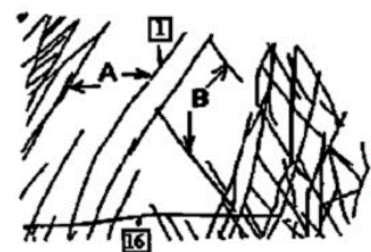

(1)

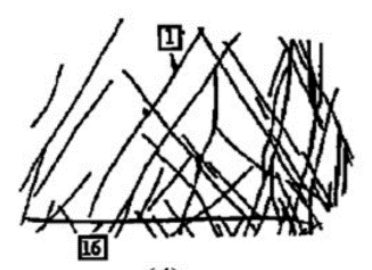

(4)

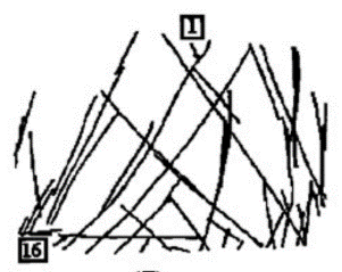

(7)

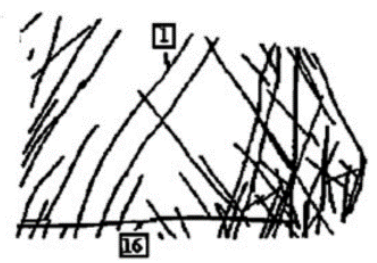

(2)

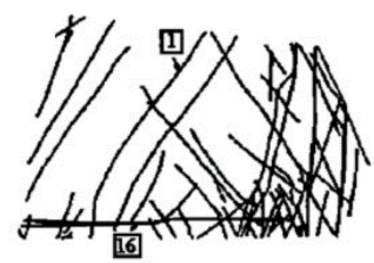

(3)

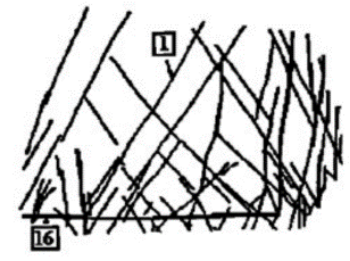

(5)

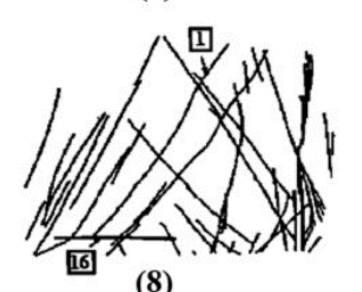

(8)

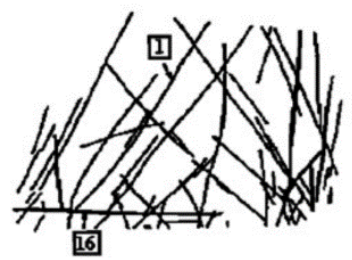

$(6)$

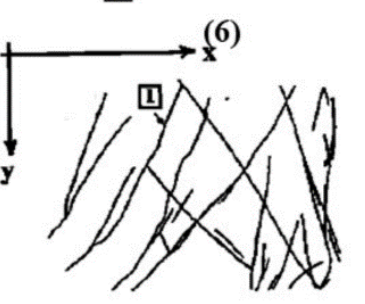

(9)

Fig. 5. Fracture trace maps of the nine parallel prismatic samples. ${ }^{56,57}$

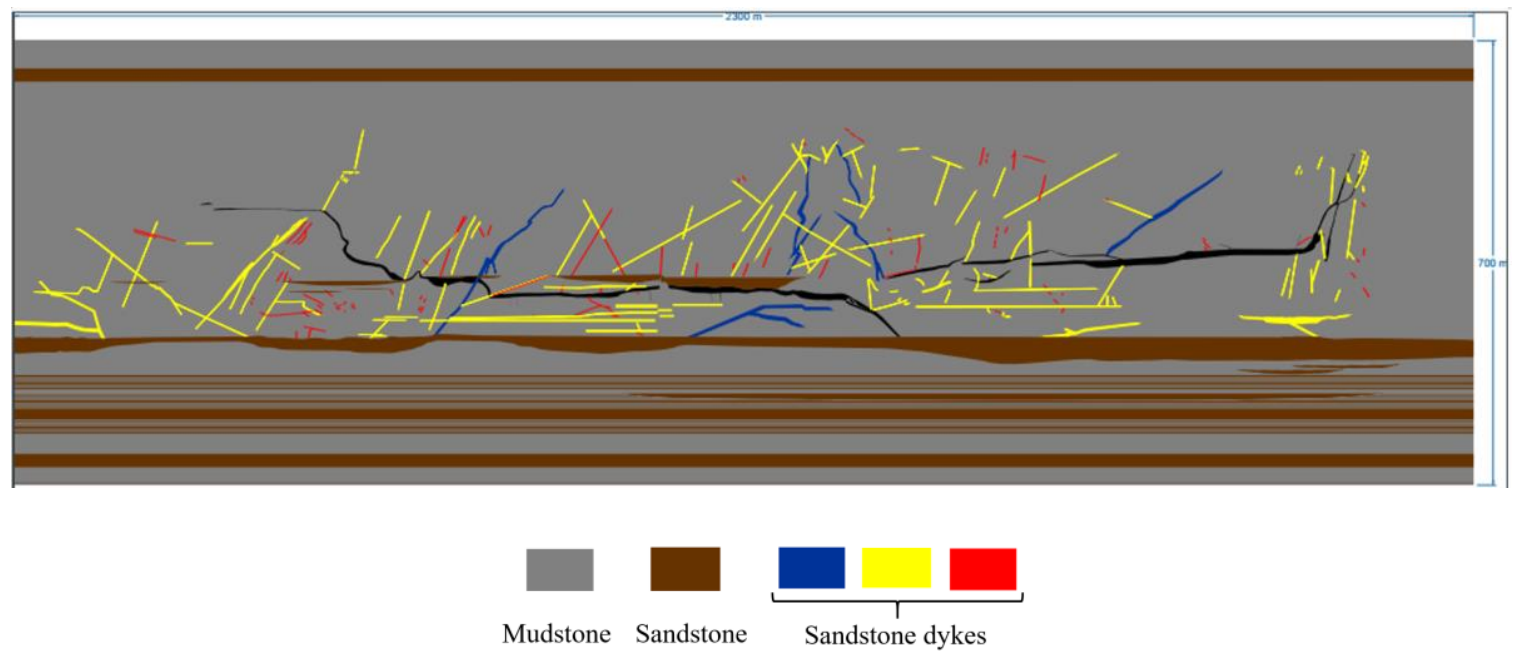

Fig. 6. Geological setting of a fractured sand injectite reservoir in the Panoche Giant Injection Complex (PGIC). ${ }^{59}$ This image is shown in the $\mathrm{x}$-axis (positive right) and $\mathrm{z}$-axis (positive upward) directions. 


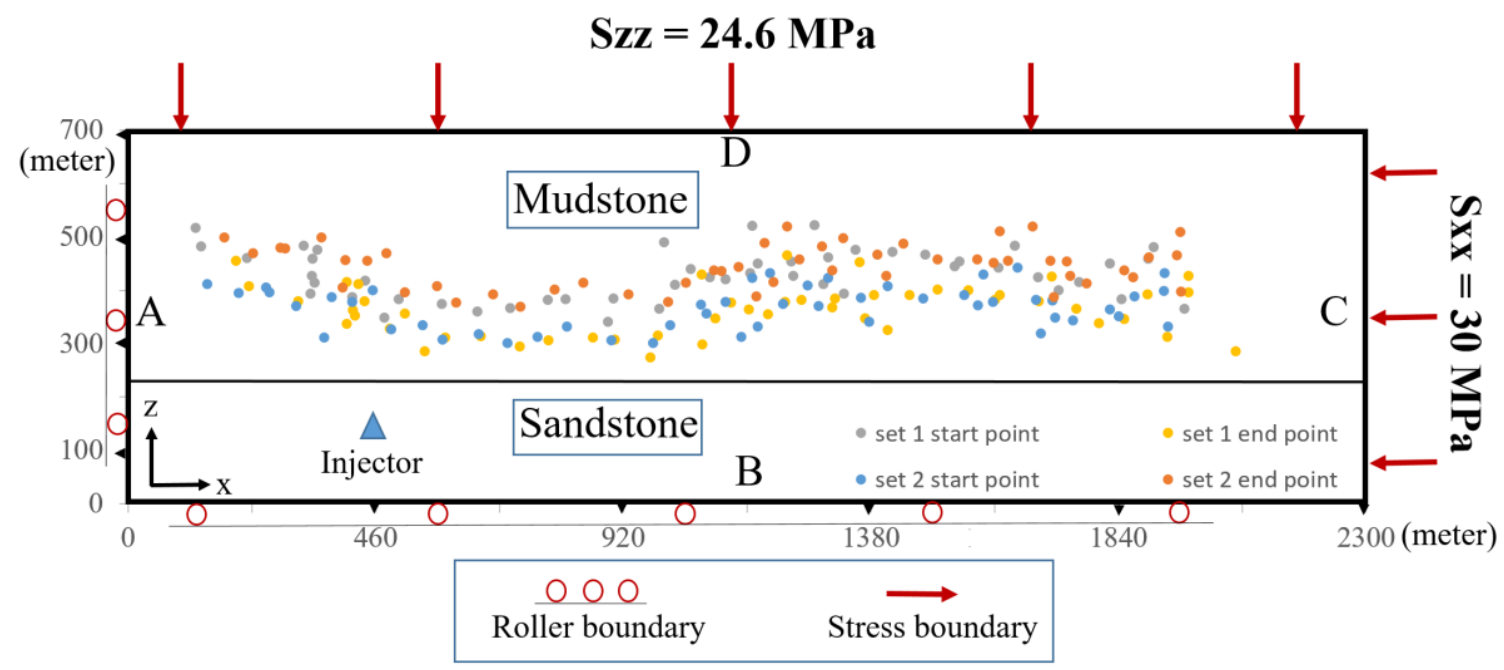

Fig. 7. A simplified reservoir model for the representation of the PGIC with a distribution of fracture starting and ending points. Sides A and B have roller boundaries. Sides C and D are stress boundaries of base case magnitudes with a horizontal principal stress ( $\mathrm{Sxx}$ ) applied to boundary $\mathrm{C}$ and a vertical principal stress (Szz) applied to boundary D.
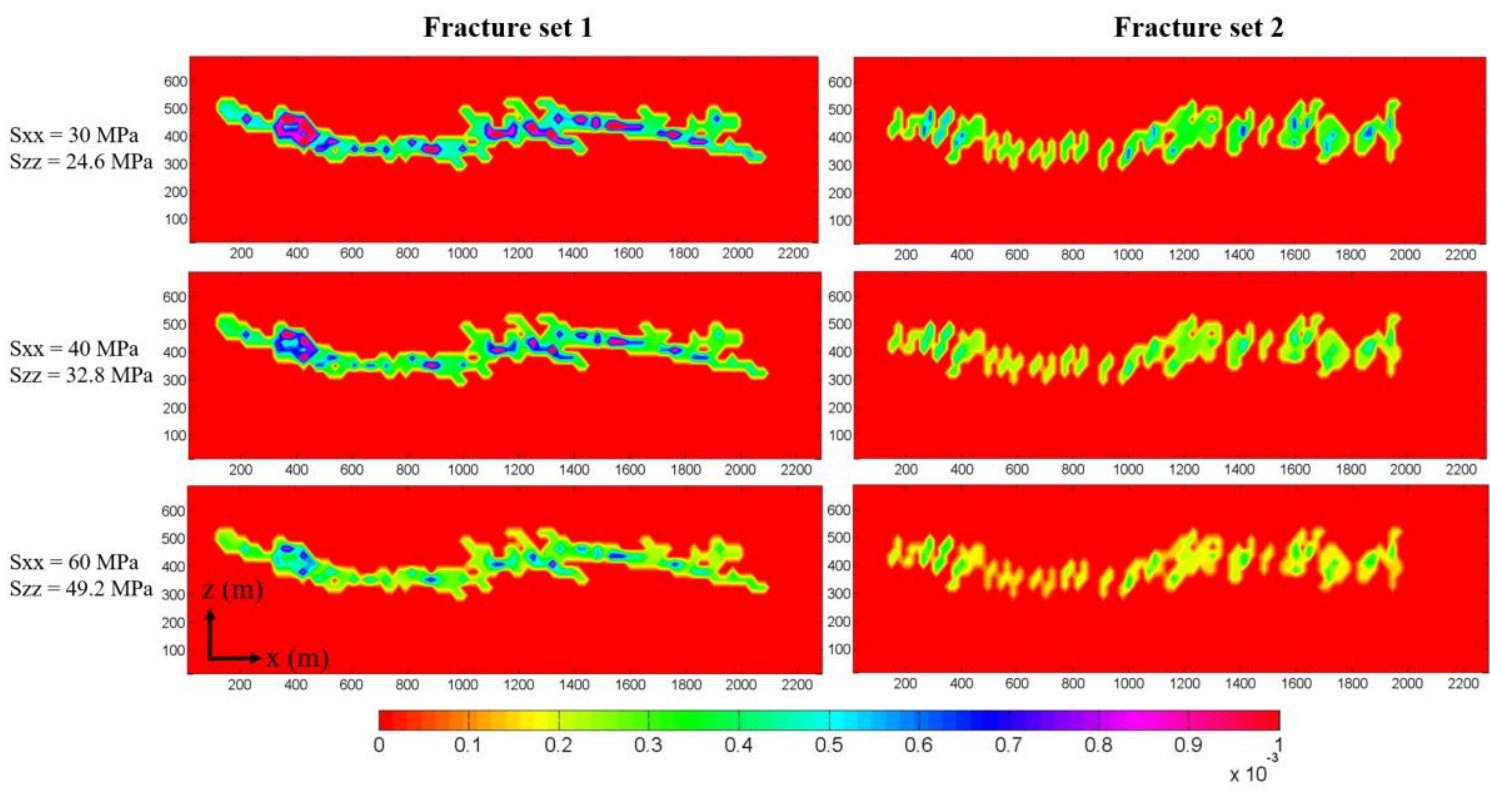

Fig. 8. Fracture aperture distributions for the two perpendicular sets of fractures under the influence of normal closure on the $115^{\text {th }}$ day. Larger stress states induce smaller apertures for both sets of fractures resulting from increased normal closure. 


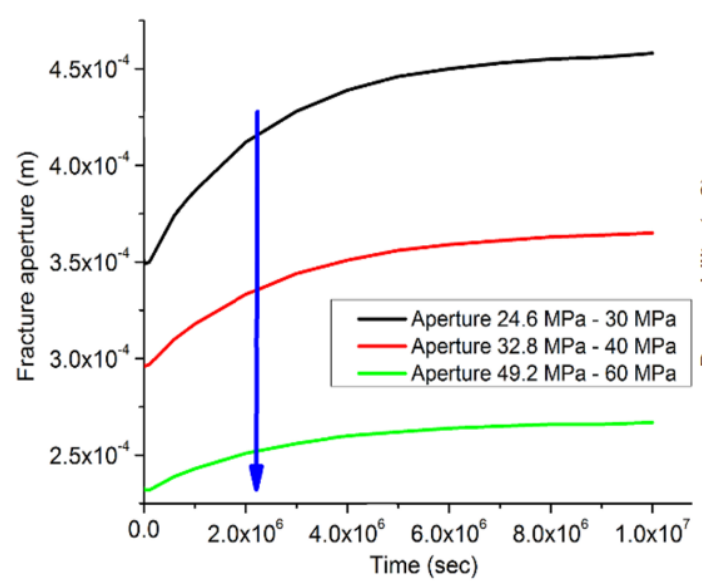

(a)

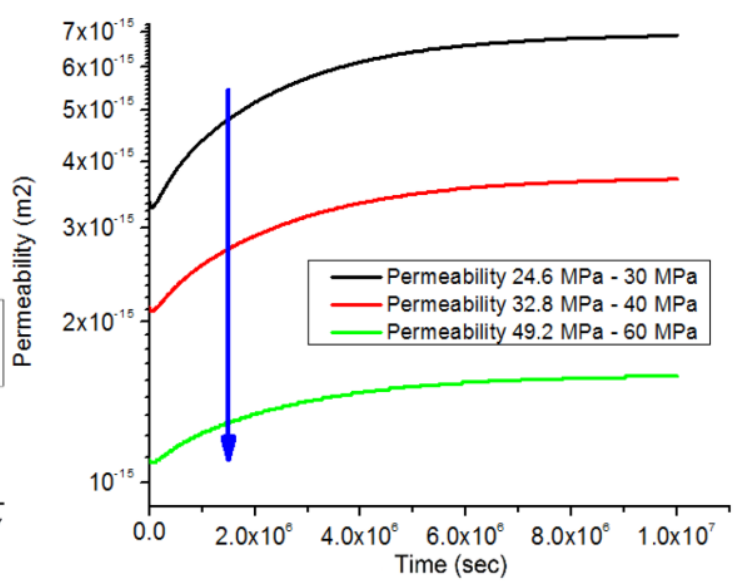

(b)

Fig. 9. (a) Evolution of fracture aperture with time. (b) Corresponding evolution of the permeability of fractured rock with time near the injector. The stress ratio is maintained constant for $1.0 \times 10^{7}$ seconds $(\sim$ 115 days). The blue arrows indicate that the reductions in aperture and permeability are due to the decreasing fracture failure potential and the dominance of increasing normal closure with the increase in stress states.

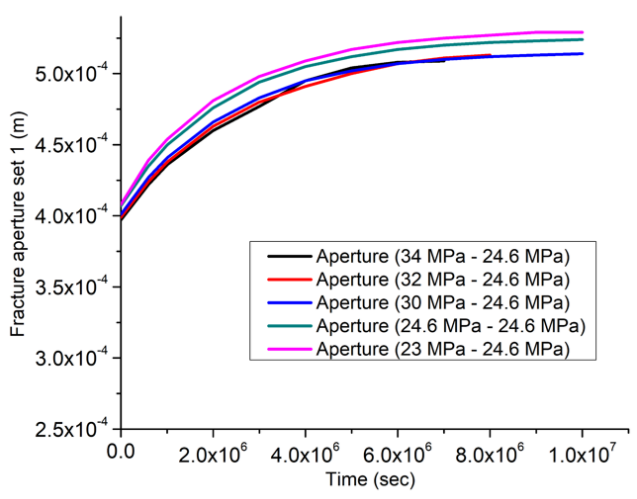

(a)

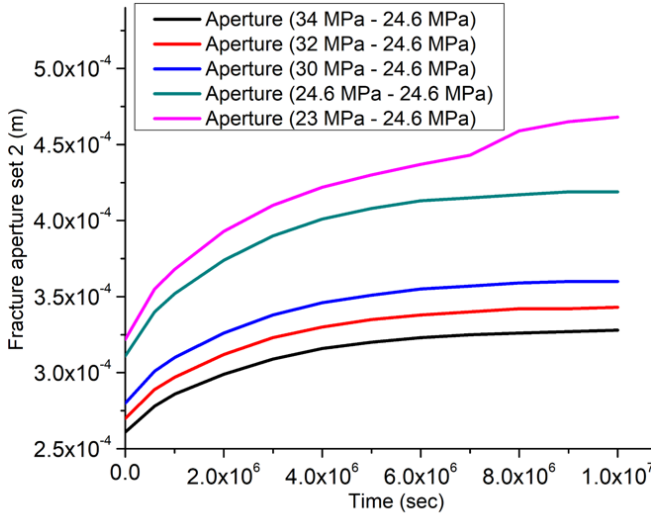

(b)

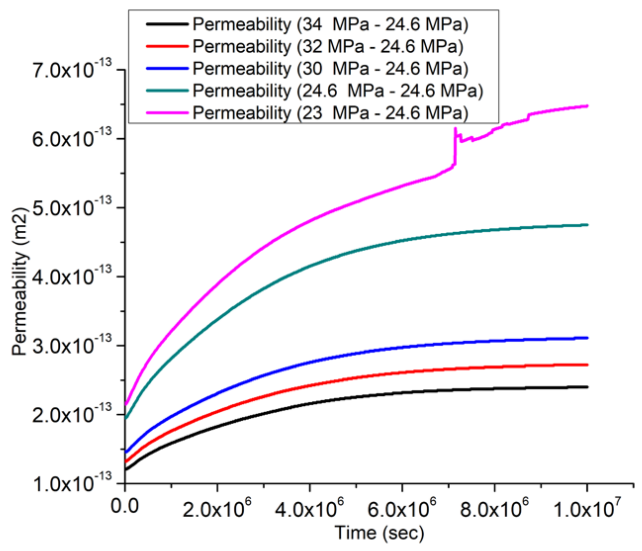

(c)

Fig. 10. (a) Aperture evolution of fracture set (set 1) with time. (b) Aperture evolution of fracture set (set 2) with time. (c) Evolution of the permeability of a fractured medium with time. 


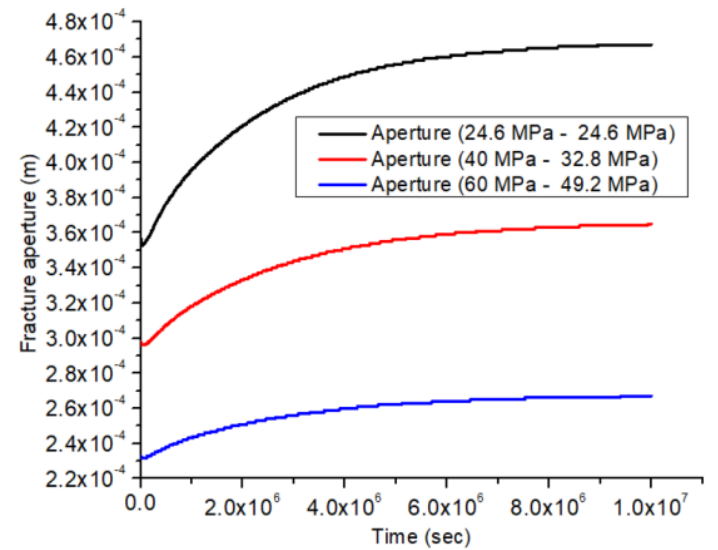

(a)

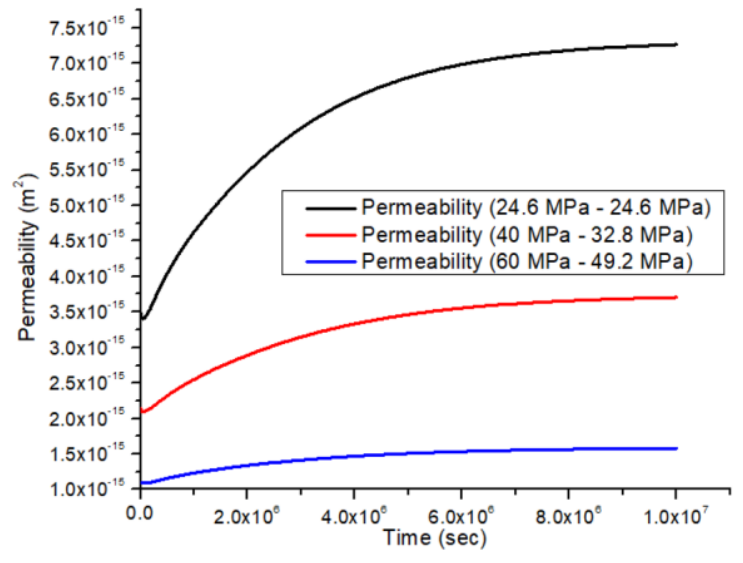

(b)

Fig. 11. Three stress states where evolution is dominated by normal closure: (a) Evolution of fracture aperture with time. (b) Evolution of permeability of the fractured rock with time.

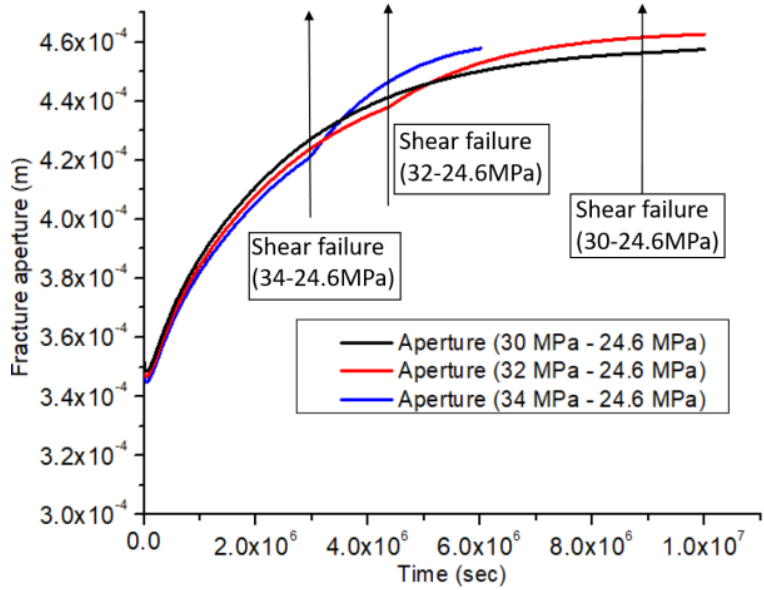

(a)

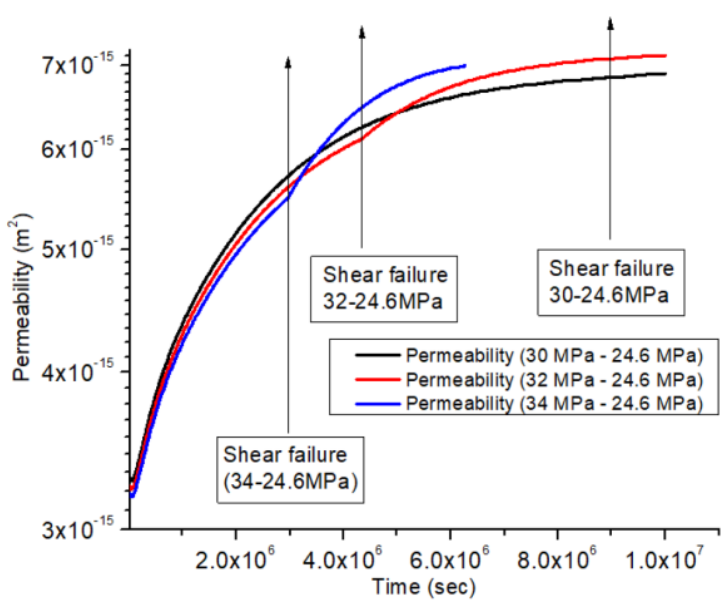

(b)

Fig. 12. For stress states with shear failure within $1 \times 10^{7}$ seconds ( 115 days) of simulation: (a) Evolution of the fracture aperture with time. (b) Evolution of the permeability of the fractured medium with time. Larger stress differences trigger earlier fracture shear failure and larger shear dilation, thus, increasing permeability more significantly.

\section{B. Tables}

Table 1. Summary of the permeability model.

\section{Fracture network}

\section{Permeability expressions}




\begin{tabular}{|c|c|}
\hline $\begin{array}{c}\text { connectivity } \\
\text { levels }\end{array}$ & $K_{\text {equ }}=\frac{K_{m}}{32 \sum_{i=1}^{n} R_{i}^{3}}$ \\
\hline $0 \leq \rho^{\prime}<2.29$ & $1-\frac{\frac{9 V}{9 V}}{\rho^{\prime}}$ \\
\hline $2.29 \leq \rho^{\prime}<4$ & $K_{\text {equ }}=K_{m}+\left[\pi \sum_{l}^{N} \rho_{l}\left\langle R^{2} b^{3}\right\rangle_{l}\left(\boldsymbol{\xi}_{\mathbf{i j}}-\mathbf{n}_{i} \mathbf{n}_{j}\right)\right] \times \frac{\left(\rho^{\prime}-2.29\right)^{2}}{\rho^{\prime}\left[100+18\left(\rho^{\prime}-2.29\right)\right]}$ \\
\hline $4 \leq \rho^{\prime}<20$ & $K_{\text {equ }}=K_{m}+\frac{2}{3}\left[\pi \sum_{l}^{N} \rho_{l}\left\langle R^{2} b^{3}\right\rangle_{l}\left(\xi_{\mathbf{i j}}-\mathbf{n}_{i} \mathbf{n}_{j}\right)\right] \times\left\{1-\frac{1}{1+\frac{7}{3} \sigma^{(-0.7)}}\left[1-\frac{0.18\left(\rho^{\prime}-2.29\right)^{2}}{\rho^{\prime}\left[1+0.18\left(\rho^{\prime}-2.29\right)\right.}\right]\right.$ \\
\hline$\rho^{\prime} \geq 20$ & $K_{\text {equ }}=K_{m}+\frac{2}{3}\left[\pi \sum_{l}^{N} \rho_{l}\left\langle R^{2} b^{3}\right\rangle_{l}\left(\boldsymbol{\xi}_{\mathbf{i j}}-\mathbf{n}_{i} \mathbf{n}_{j}\right)\right]\left(1-\frac{1}{1+\frac{7}{3} \sigma_{\max }^{\prime(-0.7)}} \frac{2 \pi}{\rho^{\prime}}\right)$ \\
\hline
\end{tabular}

Table 2. Geometric characterisation of fractures in the monitored drift. ${ }^{51}$

\begin{tabular}{|c|c|c|c|c|c|}
\hline $\begin{array}{c}\text { Fracture } \\
\text { set } i\end{array}$ & $\begin{array}{c}\text { Length } l \\
(\mathrm{~m})\end{array}$ & $\begin{array}{c}\text { Dip } \\
\text { (degrees) }\end{array}$ & $\begin{array}{c}\text { Strike } \\
\text { (degrees) }\end{array}$ & Spacing $s(\mathrm{~m})$ & Fraction $f_{i}$ \\
\hline Set 1 & 2.19 & 76 & 113 & 0.93 & 0.20 \\
\hline Set 2 & 1.11 & 85 & 173 & 0.36 & 0.25 \\
\hline Set 3 & 1.61 & 53 & 8 & 0.79 & 0.20 \\
\hline Set 4 & 1.38 & 12 & 245 & 0.51 & 0.35 \\
\hline
\end{tabular}

Table 3. The equivalent permeability of the monitored fractured drift from different models and laboratory.

\begin{tabular}{|c|c|c|c|c|}
\hline Models & $\begin{array}{c}\text { Permeability } \\
\text { of fractured } \\
\text { rock mass } \\
\left(\mathrm{m}^{2}\right)\end{array}$ & $\begin{array}{c}\text { Relative error of } \\
\text { permeability } \\
\left(\varepsilon_{k}=\frac{k_{\text {lab }}-k_{\text {model }} \mid}{k_{\text {lab }}}\right.\end{array}$ & $\begin{array}{c}\text { Conductivity } \\
\text { of fractured } \\
\text { rock mass } \\
(\mathrm{m} / \mathrm{s})\end{array}$ & $\begin{array}{c}\text { Relative error of } \\
\text { conductivity } \\
\left(\varepsilon_{\sigma}=\frac{\left|\sigma_{\text {lab }}-\sigma_{\text {model }}\right|}{\sigma_{\text {lab }}}\right)\end{array}$ \\
\hline Snow $^{16}$ & $2.26 \times 10^{-16}$ & 25.5 & $1.97 \times 10^{-9}$ & 19.1 \\
\hline $\mathrm{Oda}^{19}$ & $1.82 \times 10^{-16}$ & 20.4 & $1.58 \times 10^{-9}$ & 15.1 \\
\hline $\begin{array}{c}\text { Applied } \\
\text { Model }\end{array}$ & $5.31 \times 10^{-18}$ & 0.38 & $4.62 \times 10^{-11}$ & 0.53 \\
\hline Laboratory & \multicolumn{2}{|c|}{$8.52 \times 10^{-18}$} & \multicolumn{2}{|c|}{$9.80 \times 10^{-11}$} \\
\hline
\end{tabular}

Table 4. Laboratory results of the monitored fractured drift in the Fanay Augeres Mine. ${ }^{55,66}$ 


\begin{tabular}{|c|c|c|c|c|c|}
\hline $\begin{array}{c}\text { Fracture } \\
\text { set } m\end{array}$ & $\begin{array}{c}\text { Fracture } \\
\text { length } l_{i}(m)\end{array}$ & $\begin{array}{c}\text { Fracture } \\
\text { number } N_{f, i}\end{array}$ & $\begin{array}{c}\text { Aperture } b_{i} \\
(m)\end{array}$ & $\begin{array}{c}\text { Dip* } \\
(\text { degree })\end{array}$ & $\begin{array}{c}\text { Strike** } \\
\text { (degree) }\end{array}$ \\
\hline 1 & 0.71 & 599 & $2.84 \times 10^{-4}$ & -2.95 & 231 \\
\hline 2 & 1.14 & 102 & $3.07 \times 10^{-4}$ & 0.27 & 250 \\
\hline 3 & 0.69 & 185 & $3.02 \times 10^{-4}$ & 1.5 & 66 \\
\hline 4 & 0.53 & 436 & $3.21 \times 10^{-4}$ & 80.6 & 1 \\
\hline 5 & 0.82 & 1098 & $2.96 \times 10^{-4}$ & 88 & 276 \\
\hline
\end{tabular}

*Dips are measured counter-clockwise from horizontal.

**These are standard spherical coordinates with positive $\mathrm{x}$-axis pointing north and positive y-axis pointing to the west. Mean strikes after geostatistical analysis are listed.

Table 5. The equivalent permeability of the monitored fractured drift from different models and laboratory.

\begin{tabular}{|c|c|}
\hline Models & Permeability of fractured rock mass $\left(\mathrm{m}^{2}\right)$ \\
\hline Snow $^{16}$ & $2.3 \times 10^{-9}$ \\
\hline Oda $^{19}$ & $2.14 \times 10^{-9}$ \\
\hline Applied Model & $4.11 \times 10^{-14}$ \\
\hline Laboratory $^{55}$ & From $10^{-14}$ to $10^{-13}$ \\
\hline
\end{tabular}

Table 6. Fracture parameters of the fractured rock. ${ }^{56}$

\begin{tabular}{|c|c|c|c|}
\hline Fracture set & Dip* (degree) & Strike** (degree) $^{*}$ & Fraction \\
\hline A & -30 & 45 & 0.65 \\
\hline B & 30 & 110 & 0.35 \\
\hline
\end{tabular}

*Dips are measured counter-clockwise from horizontal.

**The strike of fracture set A ranges from 30 to 60 degrees. The average strike is applied.

Table 7. The equivalent permeability of the monitored fractured drift from different models and laboratory.

\begin{tabular}{|c|c|}
\hline Models & Permeability of fractured rock mass $\left(\mathrm{m}^{2}\right)$ \\
\hline Snow $^{16}$ & $2.47 \times 10^{-15}$ \\
\hline Oda $^{19}$ & $1.32 \times 10^{-15}$ \\
\hline Applied Model & $1.59 \times 10^{-17}$ \\
\hline Laboratory $^{55}$ & $2.32 \times 10^{-17}$ \\
\hline
\end{tabular}


Table 8. Initial reservoir properties. ${ }^{45,60}$

\begin{tabular}{|c|c|}
\hline Parameter (unit) & Magnitude \\
\hline Bulk modulus (GPa) & 25 \\
\hline Poisson's ratio (v) & 0.25 \\
\hline Sandstone matrix permeability $\left(\mathrm{m}^{2}\right)$ & $4.80 \times 10^{-14}$ \\
\hline Mudstone matrix permeability $\left(\mathrm{m}^{2}\right)$ & $1.00 \times 10^{-16}$ \\
\hline Sandstone matrix porosity & 0.25 \\
\hline Mudstone matrix porosity & 0.05 \\
\hline Biot coefficient & 0.88 \\
\hline Water viscosity $(\mathrm{cP})$ & $3.55 \times 10^{-4}$ \\
\hline Fluid compressibility (1/MPa) & $4.20 \times 10^{-4}$ \\
\hline Reservoir temperature $\left({ }^{\circ} \mathrm{C}\right)$ & 50 \\
\hline Pore pressure $(\mathrm{MPa})$ & 12 \\
\hline Injection pressure $(\mathrm{MPa})$ & 22 \\
\hline Fracture friction angle $(\mathrm{degree})$ & 27 \\
\hline Fracture dilation angle $(\mathrm{degree})$ & 3 \\
\hline Fracture cohesion $(\mathrm{MPa})$ & 0 \\
\hline Sandstone cohesion $(\mathrm{MPa})$ & $1.00 \times 10^{6}$ \\
\hline Mudstone cohesion $(\mathrm{MPa})$ & $3.00 \times 10^{6}$ \\
\hline
\end{tabular}

Table 9. Sensitivity tests of the effects of applied boundary stresses on the evolution of aperture and permeability.

\begin{tabular}{|c|c|c|c|}
\hline & Scenario settings & $\mathrm{Sxx}(\mathrm{MPa})$ & Szz (MPa) \\
\hline \multirow{3}{*}{ Scenario 1} & \multirow{3}{*}{$\begin{array}{l}\text { Stresses of constant ratio } \\
\quad(\mathrm{Szz} / \mathrm{Sxx}=0.82)\end{array}$} & 30 & 24.6 \\
\hline & & 40 & 32.8 \\
\hline & & 60 & 49.2 \\
\hline \multirow{5}{*}{ Scenario 2} & \multirow{5}{*}{ Deviatoric stresses } & 23 & 24.6 \\
\hline & & 24.6 & 24.6 \\
\hline & & 30 & 24.6 \\
\hline & & 32 & 24.6 \\
\hline & & 34 & 24.6 \\
\hline
\end{tabular}

Table 10. Shear failure state of fractures and mechanisms for aperture evolution.

\begin{tabular}{|c|c|c|}
\hline $\begin{array}{c}\text { Evolution } \\
\text { mechanisms }\end{array}$ & $\begin{array}{c}\text { Sxx } \sim \text { Szz } \\
(\mathrm{MPa})\end{array}$ & $\begin{array}{c}\text { Shear failure status } \\
\text { of fractures }\end{array}$ \\
\hline \multirow{3}{*}{ Normal closure } & $24.6 \sim 24.6$ & \multirow{3}{*}{ No fracture failure } \\
\cline { 2 - 2 } & $40 \sim 32.8$ & \\
\cline { 2 - 2 } & $60 \sim 49.2$ & \\
\hline
\end{tabular}




\begin{tabular}{|c|c|c|}
\hline \multirow{4}{*}{$\begin{array}{c}\text { Normal closure } \\
\text { and shear dilation }\end{array}$} & $23 \sim 24.6$ & \multirow{2}{*}{ Fracture set 2 fails } \\
\cline { 2 - 2 } & $30 \sim 24.6$ & \multirow{4}{*}{ Fracture set 1 fails } \\
\cline { 2 - 2 } & $32 \sim 24.6$ & \\
\cline { 2 - 2 } & $34 \sim 24.6$ & \\
\hline
\end{tabular}

\section{References}

[1] Duranti D, Hurst A. Fluidization and injection in the deep-water sandstones of the Eocene Alba Formation (U.K. North Sea). Sedimentology. 2004;51:503-531.

[2] Hamberg L, Jepsen AM, Borch NT, Dam G, Engkilde MK, Svendsen JB. Mounded structures of injected sandstones in deep-marine Paleocene reservoirs, Cecile field, Denmark. AAPG Memoir. 2007;87:69-79.

[3] Cosgrove JW. Hydraulic fracturing during the formation and deformation of a basin: A factor in the dewatering of low-permeability sediments. AAPG Bulletin. 2001;85: 737748.

[4] Jolly RJH, Lonergan L. Mechanisms and control on the formation of sand intrusions.

J. Geol. Soc. 2002;159:605-617.

[5] Cartwright JA. Regionally extensive emplacement of sandstone intrusions: A brief review. Basin Research. 2010;22:502-516.

[6] Taylor BJ. Sedimentary dikes, pipes and related structures in the Mesozoic sediments of southeastern Alexander Island. Antarct. Sci. 1982;51:1-42.

[7] Hurst A, Scott A, Vigorito M. Physical characteristics of sand injectites. Earth Sci. Rev. 2011;106:215-246.

[8] Huuse M, Cartwright JA, Gras R, Hurst A. Kilometer-scale sandstone intrusions. In: Proceedings of the 6th petroleum geology conference. London; 1 January 2005. p. $1577-$ 1594.

[9] Hurst A, Cartwright JA, Duranti D. Fluidization structures produced by upward injection of sand through a sealing lithology. Geol. Soc. Spec. Publ. 2003;216:123-137. [10] Cartwright JA, Huuse M, Aplin A. Seal bypass systems. AAPG Bulletin. 2007;91:1141-1166. 
[11] Hurst A, Cartwright JA. Implications for hydrocarbon exploration and production. AAPG Memoir. 2007;87:274.

[12] Scott A, Hurst A, Vigorito M. Outcrop-based reservoir characterization of a kilometer-scale sand-injectite complex. AAPG Bulletin. 2013;97:309-343.

[13] Hurst A, Huuse M. Subsurface sand remobilization and injection: implications for oil and gas exploration and development. Introduction of the Conference of the Geological Society. London; 22-23 March 2017. p. 1.

[14] Hurst A, Huuse M, Cartwright JA, Duranti D. Sand injectites in deep-water clastic reservoirs: Are they there and do they matter? AAPG Studies in Geology. 2007;56:24. [15] Briedis NA, Bergslien D, Hjellbakk A, Hill RE, Moir GJ. Recognition criteria, significance to field performance, and reservoir modeling of sand injections in the Balder field, North Sea. AAPG Memoir. 2007;87:91-102.

[16] Snow D. Anisotropic Permeability of Fractured Media. Water Resour. Res. 1969;5:1273-1289.

[17] Zoorabadi M. A new method to estimate the permeability of rock mass around tunnels. Australian Tunnelling Society. 2013.

[18] Witherspoon PA, Wang J, Iwai K, Gale J. Validity of cubic law for fluid-flow in a deformable rock fracture. Water Resour. Res. 1980;16:1016-1024.

[19] Oda M. An equivalent continuum model for coupled stress and fluid flow analysis in jointed rock masses. Water Resource Res. 1986; 22:1845-1856.

[20] Jafari A, Babadagli T. Equivalent Fracture Network Permeability of MultilayerComplex Naturally Fractured Reservoirs. Transport Porous Med. 2012;91:339-362. [21] Odling N. Scaling and connectivity of joint systems in sandstones from western Norway. J. Struct. Geol. 1997;19:1257-1271.

[22] Bourbiaux B. A rapid and efficient methodology to convert fractured reservoir images into a dual-porosity model. In: Proceedings of SPE Annual Technical Conference and Exhibition, Texas. 5-8 Oct 1998. p. 785-799.

[23] de-Dreuzy J, Davy P, Bour O. Hydraulic properties of two-dimensional random fracture networks following a power law length distribution: 1. Effective connectivity. 2. Permeability of networks based on lognormal distribution of apertures. Water Resour Res. 2001;37:2079-2095. 
[24] Mourzenko VV, Thovert JF, Adler PM. Macroscopic permeability of threedimensional fracture networks with power-law size distribution. Physical Review E. 2004;69:066307(1-13).

[25] Mourzenko VV, Thovert JF. Percolation of three-dimensional fracture networks with power-law size distribution. Physical Review E. 2005;72:036103(1-14).

[26] Min KB, Rutqvist J, Tsang CF, Jing L. Stress-dependent permeability of fractured rock masses: a numerical study. Int. J. Rock Mech. Min. Sci. 2004;41:1191-1210. [27] Zhou C, Sharma R, Chen Y, Rong G. Flow-stress coupled permeability tensor for fractured rock masses. Int. J. Numer. Anal. Meth. Geomech. 2008;32:1289-1309. [28] Barton C, Larsen E. Fractal geometry of two-dimensional fracture networks at Yucca Mountain, Southwestern Nevada. Environ. In: Proceedings of the international symposium on fundamentals of rock joints; 15-20 September 1985. p. 77-84.

[29] Jafari A, Babadagli T. Effective fracture network permeability of geothermal reservoirs. Geothermics. 2011;40:25-38.

[30] Leung C, Zimmerman R. Estimating the hydraulic conductivity of two-dimensional fracture networks using network geometric properties. Transp Porous Med. 2012;93: 777797.

[31] Broadbent S, and Hammersley J. Percolation processes. I. Crystals and mazes. Camb Philos Soc .1957.

[32] Lang P, Paluszny A, Zimmerman R. Permeability tensor of three-dimensional fractured porous rock and a comparison to trace map predictions. J. Geophys. Res. Solid Earth. 2014;119.

[33] Berkowitz B. Analysis of fracture network connectivity using percolation theory. Math Geol. 1995;27:467-183.

[34] Sisavath S, Mourzenko VV, Genthon P, Thovert JF, Adler P. Geometry, percolation and transport properties of fracture networks derived from line data. Geophys. J. Int. 2004;157:917-934.

[35] Rossen W. Theory of mobilization pressure gradient of flowing foams in porous media. J. Colloid Interface Sci. 1990;136:1-16.

[36] Jafari A. Permeability estimate of fracture networks. PhD Thesis. University of Alberta, Edmonton, Canada; 2011. 
[37] Mourzenko VV, Trovert JF. Permeability of isotropic and anisotropic fracture networks, from the percolation threshold to very large densities. Phys. Rev. 2011;84:120.

[38] Trovert JF, Adler PM. c Geophys. Res. Lett. 2004;31:L22502.

[39] Bogdanov I. et al. Effective permeability of fractured porous media with powerlaw distribution of fracture sizes. The American Physical Society. 2007.

[40] Gan Q, Elsworth D. A continuum model for coupled stress and fluid flow in discrete fracture networks. Geomech. Geophys. Geo-energ. Geo-resour. 2016;2:43-61.

[41] Zhang X, Sanderson D. Fractal structure and deformation of fractured rock masses. In:Fractals and Dynamic Systems in Geoscience, Kruhl JH, editor. Springer, Berlin, Heidelberg; 1994. pp. 37-52.

[42] Cundall PA. A discontinuous future for numerical modelling in geomechanics? Geotech. Eng. 2001;149:41-47.

[43] Taron J, Elsworth D, Min KB. Numerical simulation of thermal-hydrologicmechanical-chemical processes in deformable, fractured porous media. Int J Rock Mech. 2009;46:842-854.

[44] Itasca Consulting Group, Inc. FLAC3D. Fast Lagrangian Analysis of Continua in Three-Dimensions, ver. 5.0. Itasca, Minneapolis. 2000.

[45] Gan Q, Elsworth D. Analysis of fluid injection-induced fault reactivation and seismic slip in geothermal reservoirs. J. Geophys. Res. Solid Earth. 2014;119:3340-3353. [46] Taron J, Elsworth D. Coupled mechanical and chemical processes in engineered geothermal reservoirs with dynamic permeability. Int J Rock Mech Min Sci. 2010; 47:1339-1348.

[47] Baghbanan A, Jing L. Hydraulic properties of fractured rock masses with correlated fracture length and aperture. Int J Rock Mech Min Sci. 2007;44:704-719.

[48] Balberg I, Binenbaum N, Wagner N. Percolation Thresholds in the ThreeDimensional Sticks System. Phys. Rev. Lett.1984;52:1465-1468.

[49] Williams KE. The permeability of overpressure shale seals and of source rock reservoirs is the same. In: Proceedings of AAPG Annual Convention and Exhibition, Long Beach, California; 22-25 April 2012. 
[50] Koudina N, Gonzalez-Garcia R, Thovert JF, Adler PM. Permeability of threedimensional fracture networks. Phys. Rev. E. 1998;57:4466-4479.

[51] Rouleau A, Gale JE. Statistical characterization of the fracture system in the Stripa Granite, Sweden. Int. J. Rock Mech, Min Sci \& Geomech, Abstr. 1985;22:353-367. [52] Wilson CR, Witherspoon PA, Long JCS, Galbraith RM, Dubois AO, McPherson MJ. Large-scale hydraulic conductivity measurements in fractured granite. Int. J. Rock. Mech. Min. Sci. \& Geomech. 1983;20:269-276.

[53] Lundstrom L, Stille H. Large scale permeability test of the granite in the Stripa Mine and thermal conductivity test. In: Lawrence Berkeley Laboratory, Technical Project Report No.2, Swedish Nuclear Fuel Safety Program. 1978.

[54] Gros, Y., Etude structurale de la mine de Fanay-Augeres-Géométrie, cinématique et chronologic des fractures, reportBur. de Rech. Géol. el Min., Orleans, France. 1982. [55] Long JCS, Billaux DM. From field data to fracture network modeling: An example incorporating spatial structure. Water Resour Res. 1987;23:1201-1216.

[56] Gonzalez-Garcia R, Huseby O, Trovert JF, Ledesert B, Adler PM. Threedimensional characterization of a fractured granite and transport properties. J. Geophys. Res. 2000;105:21387-21401.

[57] Ledesert B, Dubois J, Velde B, Meunier A, Genter A, Badri A. Geometrical and fractal analysis of a three-dimensional hydrothermal vein network in a fractured granite. J. Volcanol. Geotherm. Res. 1993;56:267-280.

[58] Bureau D, Mourgues R, Cartwright J. Use of a new artificial cohesive material for physical modelling: application to sandstone intrusions and associated fracture networks. J. Struct. Geol. 2014;66:223-236.

[59] Grippa, A. Unpublished results. University of Aberdeen, Aberdeen, UK. 2015.

[60] McTigue DF. Flow to a heated borehole in porous, thermoelastic rock: analysis. Water Resour Res. 1990;26:1763-1774.

[61] Jaeger JC, Cook NGW, Zimmerman RW. In: Fundamentals of Rock Mechanics, Fourth Edition. Blackwell Publishing; 2007.

[62] Ebigbo A, Lang PS, Paluszny A, Zimmerman RW. Inclusion-based effective medium models for the permeability of a 3D fractured rock mass. Transp Porous Med. 2016;113:137-158. 
[63] Sævik PN, Berre I, Jakobsen M, Lien M. A 3D computational study of effective medium methods applied to fractured media. Transp Porous Med. 2013;100:115-142. [64] Gale JE, Rouleau A. Progress in the hydrogeological characterization of the Sripa Site. Technical information report No. 49, Lawrence Berkeley Laboratory, California. 1982.

[65] Trovert JF, Mourzenko VV. Percolation in three-dimensional fracture networks for arbitrary size and shape distributions. Phys. Rev. 2017;95:042112(1-14).

[66] Billaux D, Chiles JP, Hestir K, Long J. Three-dimensional statistical modelling of a fractured rock mass - an example from the Fanay-Augeres Mine. Int. J. Rock. Mech. Min. Sci. \& Geomech. Abstr. 1989;26:281-299.

[67] Malinouskaya I, Thovert JF, Mourzenko VV, Adler PM, Shekhar R, Agar S, Rosero E, Tsenn M. Fracture analysis in the Amellago outcrop and permeability predictions. Petroleum Geoscience. 2014;20:93. 